\title{
Combinatorial Evolution of Biomimetic Magnetite Nanoparticles.
}

Jos J.M. Lenders ${ }^{\mathrm{a}, \mathrm{b}}$, Lukmaan A. Bawazer ${ }^{\mathrm{c}}$, David C. Green ${ }^{\mathrm{c}}$, Harshal R. Zope ${ }^{\mathrm{d} \#}$, Paul H.H. Bomans $^{\mathrm{a}, \mathrm{b}}$, Gijsbertus de With ${ }^{\mathrm{a}}$, Alexander Kros ${ }^{\mathrm{d}}$, Fiona C. Meldrum ${ }^{\mathrm{c}, *}$, and Nico A.J.M. Sommerdijk ${ }^{\mathrm{a}, b^{*}}$

Dr. Jos J.M. Lenders, Dr. Paul H.H. Bomans, Prof. Dr. Gijsbertus de With, Prof. Dr. Nico A.J.M. Sommerdijk*

Laboratory of Materials and Interface Chemistry and Center of Multiscale Electron Microscopy, Department of Chemical Engineering and Chemistry, Eindhoven University of Technology, P.O. Box 513, 5600 MB Eindhoven, The Netherlands

E-mail: $\underline{\text { n.sommerdijk@tue.nl }}$

Dr. Jos J.M. Lenders, Paul H.H. Bomans Prof. Dr. Nico A.J.M. Sommerdijk Institute for Complex Molecular Systems, Eindhoven University of Technology, P.O. Box 513, 5600 MB Eindhoven, The Netherlands

Dr. Lukmaan A. Bawazer, Dr. David C. Green, Prof. Fiona Meldrum*

School of Chemistry, University of Leeds, Woodhouse Lane, Leeds LS2 9JT, United Kingdom

E-mail: f.meldrum@leeds.ac.uk

Dr. Harshal R. Zope, Prof. Alexander Kros

Leiden Institute of Chemistry, Leiden University, P.O. Box 9502, 2300 RA Leiden, The Netherlands

\$ Present address: Department of Bioengineering, Stanford University, 443 Via Ortega, Stanford, CA 94304, United States of America;

\# Present address: Laboratory of Nanomedicine and Biomaterials and Brigham and Women's Hospital, Harvard Medical School", 75 Francis Street, Boston, MA 02115, United States of America

Keywords:

biomineralization, bioinspired, genetic algorithms, high-throughput screening, iron oxides 


\begin{abstract}
Inspired by Nature's capacity to synthesize well-defined inorganic nanostructures, such as the magnetite particles produced by magnetotactic bacteria, genetic algorithms are employed to combinatorially optimize the aqueous synthesis of magnetite ( $\mathrm{Fe} 3 \mathrm{O} 4)$ nanoparticles through the action of copolypeptide additives. An automated dispensing system is used to prepare and rapidly screen hundreds of mineralization reactions with randomized conditions, varying ferrous iron, base, oxidant and polypeptide chemistry. Optimization over multiple generations allows identification of conditions under which the copolypeptides promote magnetite formation where this does not occur in their absence. It is found that nanoparticle size, size distribution, and shape can be tuned by the concentrations and compositions of the copolypeptides, and that the reaction $\mathrm{pH}$ is the most important factor in controlling the crystalline phase. This approach should be broadly applicable to the syntheses of solid-state materials and represents a valuable strategy for extending biomimetic mineralization to the production of technological materials.
\end{abstract}




\section{Introduction}

Magnetite formation by magnetotactic bacteria is an excellent example of biologically controlled nanoparticle synthesis, ${ }^{[1]}$ where specialized biopolymers function in concert to regulate nanoparticle size, morphology, and polymorph, ${ }^{[2]}$ Synthetic strategies to mimic magnetite biomineralization are widely sought, ${ }^{[3]}$ both to create simplified model systems that can reveal key mineralizing mechanisms, and to enable sustainable low-temperature routes to industrial materials production. ${ }^{[4]}$ However, biogenic magnetite formation emerges from a highly complex reaction space with approximately 100 proteins contributing to the mineralization system in magnetotactic bacteria. ${ }^{[5]}$ Further, "iron oxide / hydroxide" is also a complex mineral system that comprises 16 different crystalline phases, ${ }^{[6]}$ of which many are more stable than magnetite under simple aqueous conditions. It has therefore proven difficult to synthesize phase-pure magnetite nanocrystals with well-controlled dimensions and morphology under biomimetic, low-temperature aqueous conditions.

Current synthetic routes to highly monodisperse magnetite nanoparticles require hydrothermal conditions ${ }^{[7]}$ or high-boiling solvents, ${ }^{[8]}$ and often employ costly organometallic precursors. Previous biomimetic studies have achieved some success by controlling reactant supply to influence the average size and magnetic properties of magnetite crystals, ${ }^{[9]}$ and negatively or positively charged polymers have been used as protein analogues to control the morphology, size distribution and solubility of magnetite nanoparticles. ${ }^{[10]}$ However, as yet, no aqueous-based synthesis has succeeded in generating monodisperse, phase-pure magnetite in aqueous solutions to rival the nanoparticles produced in organic solvents - or indeed, in Nature.

The complexity of aqueous magnetite precipitation makes this system well suited to exploration via combinatorial approaches, where these can sample much larger reaction spaces than can be achieved in conventional experiments. To productively harness such multidimensional reaction spaces it is essential that we can rapidly assess and optimize reaction 
conditions to achieve defined outcomes. One approach that is beginning to be explored is the application of genetic algorithms, where these are inspired by the mechanisms of diversification and selection in natural biological evolution. ${ }^{[11]}$ After a first-round of screening, which identifies the most promising reaction products, the "lead conditions" under which these products were generated are used to create a second generation of reaction conditions. The reaction landscape can then be further narrowed in successive screening rounds according to the product characteristics that determine reaction selection (i.e., the fitness function). The potential of this strategy has been demonstrated in combinatorial chemistry, ${ }^{[12]}$ drug discovery, ${ }^{[13]}$ and high-throughput materials development, ${ }^{[14]}$ and we recently showed its value in the rapid identification of combinations of amino acids and surfactants that direct the assembly of fluorescent cadmium sulfide quantum dot superstructures. ${ }^{[15]}$

In the present study, we apply genetic algorithms to biomimetic mineralization, selecting as our goal the challenge of synthesizing phase-pure, monodisperse magnetite nanoparticles in aqueous solutions. Studying the precipitation of magnetite in the presence of different polypeptides and reaction conditions, the work described here shows how combinatorial methods, led by genetic algorithms, can provide an effective strategy for identifying the key conditions under which the organic additives are most effective for this mineralization system. We demonstrate that polypeptides can enable the formation of magnetite in aqueous solution under reaction conditions where it is otherwise impossible, and also reveal directs links between the composition of the polypeptides and the sizes of the magnetite nanoparticles.

\section{Results}

\subsection{Experimental Strategy}


While a range of techniques can be used to synthesize magnetite from aqueous solution, we selected the partial oxidation method, which only involves three essential reactants (ferrous iron $\left(\mathrm{FeCl}_{2}\right)$, base $(\mathrm{KOH})$ and oxidant $\left(\mathrm{KNO}_{3}\right),{ }^{[16]}$ and thus is well-suited to high-throughput screening experiments. A solid ferrous hydroxide precursor - white rust - is initially precipitated (Equation 1) and is then partially oxidized to magnetite (Equation 2), commonly using nitrate $\left(\mathrm{NO}_{3}{ }^{-}\right)$as the oxidant. ${ }^{[10 \mathrm{c}, 16 \mathrm{a}, 17]}$ The reaction can also be carried out in air, such that oxygen can participate as an oxidant. As the partial oxidation is controlled through the oxidation of the ferrous hydroxide precursor, ${ }^{[10 c, 16 a, 17 a, b]}$ magnetite formation is a slow and tunable process. Direct mixing of $\mathrm{Fe}^{3+} / \mathrm{Fe}^{2+}$ salts at high $\mathrm{pH}$, in contrast, gives instant magnetite formation with little possibility of control over particle size, phase purity or morphology, ${ }^{[18]}$ whereas the slow co-precipitation method using the in diffusion of ammonia requires a sealed environment for each reaction and not easily compatible with the use of a pipetting robot. ${ }^{[9 c]}$

\section{Equation 1}

$\mathrm{Fe}^{2+}{ }_{(\mathrm{aq})}+2 \mathrm{OH}^{-} \rightarrow \mathrm{Fe}(\mathrm{OH})_{2}$

\section{Equation 2}

$6 \mathrm{Fe}(\mathrm{OH})_{2}+O X \rightarrow 2 \mathrm{Fe}_{3} \mathrm{O}_{4}+6 \mathrm{H}_{2} \mathrm{O}(+R E D)$

$O X($ oxidant $)=2 \mathrm{NO}_{3}^{-}$or $\mathrm{O}_{2} ; R E D($ reductant $)=2 \mathrm{NO}_{2}^{-}$

Key to our bio-inspired approach was also the use of nine random copolypeptide additives (amino acid copolymers) to mediate the reaction. These polypeptides (EKA) have a degree of polymerization of $\sim 24$ and contain glutamic acid (E), lysine (K) and alanine (A) in a wide range of monomer compositions (Table 1). ${ }^{[19]}$ This compositional freedom allows us to explore the 
effects of both the net charge and the hydrophobicity of soluble polymer additives on mineral formation across the full parameter space. In a slow co-precipitation reaction involving the diffusion of ammonia into the solution, these polypeptides have been found to affect the nucleation and growth of magnetite nanoparticles. ${ }^{[10 d, 20]}$ They therefore serve as good candidates for our optimization studies.

Having established our basic reaction space, sets of combinatorial experiments were performed to identify the conditions which support the formation of phase-pure magnetite particles with narrow size distributions. Given the number of variables involved, genetic algorithms proved extremely valuable to rapidly identify the reaction conditions which yield particles with the desired target properties. In our biomimetic materials synthesis, the "genes" are represented by the concentrations of the polypeptides, $\mathrm{FeCl}_{2}, \mathrm{KOH}$ and $\mathrm{KNO}_{3}$, and their combination, with specific values for each species. Together these encode a given mineralization reaction (Figure 1).

Initially, many "parent" reactions are prepared with randomly chosen gene values (i.e., reagent concentrations), and the reaction products are screened for "fitness" according to their capacity to meet defined performance criteria. ${ }^{[11]}$ Due to its distinctive black color and magnetic properties, ${ }^{[6]}$ magnetite is an easily identified product, and its formation represents a convenient fitness function for rapid combinatorial screening. Once selected, "winning" genes are diversified via recombination and mutation to create a new generation of "daughter" reactions that are expected to inherit the superior properties of their "parents". By examining successful reaction conditions, each screening round provides new insight into the reaction parameter space that produces biomimetic magnetite. Detailed descriptions of the reaction conditions employed in each round of experiments is provided in the methods section

\subsection{First Generation (Parent) Experiments}


Experiments were performed using a liquid handling robot to automatically dispense the reactant solutions into 96-well plates, where the proportions of the reactants were randomly selected using a custom script. ${ }^{[15]}$ The first generation of experiments was performed in the absence and presence of the EKA polypeptides. 24 unique, copolymer-free experiments were carried out by preparing aqueous mixtures of $\mathrm{FeCl}_{2}, \mathrm{KOH}$ and $\mathrm{KNO}_{3}$, and subsequently exposing these to air, under mechanical mixing, for 24 hours at $22{ }^{\circ} \mathrm{C}$. The experiments were designed to contain up to a 2 -fold excess of base relative to oxidant, where this is expected to enable complete conversion to magnetite according to Equations 1 and 2. Strikingly, none of these experiments generated magnetite (Figure 2a, "Ctrl”), but instead formed ferrihydrite $\left(\mathrm{Fe}_{2} \mathrm{O}_{3} \cdot \mathrm{xH}_{2} \mathrm{O}\right.$, orange) and/or goethite $(\alpha-\mathrm{FeOOH}$, green). This demonstrates that the reaction conditions were too strongly oxidizing to achieve the only partial oxidation of $\mathrm{Fe}^{2+}$ that is required for magnetite formation.

The activities of the polypeptides in directing magnetite formation were then assessed by adding one of the 9 EKA polypeptides to each of the 24 mineralization reactions, yielding 216 additional experiments (Figure 2). In contrast to the control experiments, 19\% (42 of 216) of the reactions with EKA additives supported magnetite formation, where this was identified by black color formation (Figure 2a) and a visible magnetic response to a handheld neodymium disc magnet. This finding strongly suggests that the polypeptides retard the oxidation reaction, most probably by binding to the $\mathrm{Fe}^{2+} \cdot{ }^{[10 \mathrm{~d}]}$ Analysis of the data showed that a defined range of $\left[\mathrm{Fe}^{2+}\right]$ and $[\mathrm{EKA}] /\left[\mathrm{Fe}^{2+}\right]$ ratios generated magnetite (Figure $2 \mathbf{b}$, red dashed lines), although not all experiments in this parameter space were successful. Hence, the $\left[\mathrm{Fe}^{2+}\right]$ and [EKA] concentrations were designated important in the formation of magnetite and were employed as the "genes" which were targeted for diversification in the next generation of combinatorial. It 
should however be noted that similar relationships exist between the obtained phase and either the $\left[\mathrm{OH}^{-}\right] /\left[\mathrm{Fe}^{2+}\right]$ or the $\left[\mathrm{NO}_{3}{ }^{-}\right] /\left[\mathrm{Fe}^{2+}\right]$ ratio (Figure S1). Also, there were no significant differences in the abilities of the different polypeptides to generate magnetite (Figures S1c), and thus all 9 EKA polypeptides were taken forward as genetic elements in the subsequent optimization round.

\subsection{Second Generation Experiments}

The second round of screening was performed to again target reaction conditions which generate phase-pure magnetite. Reaction conditions (i.e., encoding genes) for this second screening round were produced using a genetic algorithm (Figure 3 and Experimental Section). Briefly, the 42 winning parent reactions from round 1 were randomly selected two reaction condition sets at a time, and were mated such that their $\left[\mathrm{Fe}^{2+}\right]$ and $[\mathrm{EKA}]$ genes were recombined to create two new daughter experiments. This process was repeated to generate 96 daughter reactions (Figure S2a).

Visual inspection of the reaction products demonstrated the success of this optimization process, with 44\% (42 out of 96) of experiments now showing evidence of magnetite formation (Figure 4a). Further examination by TEM and electron diffraction (Figures 4c-e) demonstrated that the EKA additives only support magnetite formation at $\mathrm{Fe}^{2+}$ concentrations $>40 \mathrm{mM}$ and in a narrow $\mathrm{pH}$ range $(\mathrm{pH}=12.7-13.0)$ as defined by $\left[\mathrm{OH}^{-}\right]_{\text {excess }}=50-100 \mathrm{mM}$. However, this magnetite product often co-precipitated with goethite (Figure 4b). Looking across the whole $\mathrm{pH}$ range, nanocrystalline ferrihydrite forms at the lowest values of $\left[\mathrm{OH}^{-}\right]$excess, poorly crystallized magnetite forms at intermediate $\left[\mathrm{OH}^{-}\right]_{\text {excess, }}$, highly crystalline magnetite forms at higher $\left[\mathrm{OH}^{-}\right]_{\text {excess, }}$ and goethite is the sole product at the highest values of $\left[\mathrm{OH}^{-}\right]$excess. Excess base, which is known to control the oxidation rate ${ }^{[16 a, 17 a]}$ as well as the $\mathrm{Fe}^{2+} / \mathrm{Fe}^{3+}$ equilibrium, ${ }^{[21]}$ 
therefore appears to influence the phase and crystallinity of the obtained products too, in concert with the EKA polypeptides as already was observed in the first generation experiment.

The TEM studies also revealed that the magnetite particles exhibited different size distributions according to the polypeptide/iron ratio and the compositions of the polypeptides (Figures 5a-c and S3a). While highly polydisperse samples comprising 5-80 nm crystals were obtained at relatively high $[\mathrm{EKA}] /\left[\mathrm{Fe}^{2+}\right]$ ratios, much narrower size distributions were achieved at lower $[\mathrm{EKA}] /\left[\mathrm{Fe}^{2+}\right]$ ratios (Figure S3a). Notably, the majority of the 9 samples which possessed a small (standard) deviation $(\sigma)$ relative to the mean diameter $(\mu)$ (with $\sigma / \mu$ $<0.3$ ) were generated using polypeptides with high A contents, demonstrating an important role for the polypeptide composition. In this round, still 7 out of the 9 EKA polypeptides produced samples with narrow size distributions under different reaction conditions (Figures S2c and S3c) and thus were carried on to the third generation experiments.

\subsection{Third Generation Experiments}

In the third and final round of optimization conducted in the present study, we targeted wellcrystallized magnetite particles with narrow size distributions. To achieve this, the 11 reaction conditions that yielded well-defined magnetite crystals with narrow size distributions were used as parents (2 experiments from round 1 and nine experiments from round 2, Figure S4), and round 3 reaction conditions were created using the genetic algorithm employed in round 2, yielding a total of 32 third generation experiments. In this generation, $\mathrm{OH}^{-}$concentrations were chosen randomly to generate $\mathrm{pH}$ values of $\mathrm{pH}=12.8-13.1,\left(\left[\mathrm{OH}^{-}\right]_{\mathrm{excess}}=65-115 \mathrm{mM}\right)$, as the second-round screening had identified the higher $\mathrm{pH}$ regime to yield well-defined magnetite 
crystals. Control sets of the 32 final reaction conditions were also prepared to examine the effects of $\mathrm{KNO}_{3}$ as the oxidant and different EKA polymer on magnetite formation (Figure 6a). In the presence of $\mathrm{KNO}_{3}$ as oxidant and different EKA polymers, all third round reactions generated magnetite (Figure 6a, leftmost reaction set), demonstrating the efficiency of the genetic optimization strategy. In the majority of cases the magnetite produced was phase-pure, and the particles exhibited well-defined morphologies and narrow size distributions $(\sigma / \mu=$ 0.25-0.30). The exceptions were reactions with low $\left[\mathrm{Fe}^{2+}\right]$ and high $\left[\mathrm{OH}^{-}\right]$excess, which gave mixtures of magnetite and goethite (Figure 6c). Control experiments performed in the absence of the polypeptides yielded goethite as the principal product and only 14/32 reactions also contained some magnetite as was clear from the black color (Figure 6a, rightmost reaction set) and magnetic response of the products. This again confirms that the polypeptides were key to the production of magnetite. It is stressed that this is not a simple $\mathrm{pH}$ effect as the polypeptides do not change the $\mathrm{pH}$ of the reaction solution.

Examination of the crystal products by TEM further confirmed that the sizes and shapes of the crystals could be tuned according to the compositions of the polypeptides. The crystals were rounded when they were small $(\sim 25 \mathrm{~nm}$, Figure $6 \mathbf{d})$ and well-facetted at sizes of $\sim 40 \mathrm{~nm}$ (Figure 6e), where these differences appeared to depend on the polypeptides used. For example, A59 supported the formation of the larger, facetted crystals, while K81 gave smaller, rounded crystals. The other reaction parameters $\left(\left[\mathrm{Fe}^{2+}\right],\left[\mathrm{OH}^{-}\right],\left[\mathrm{NO}_{3}{ }^{-}\right]\right)$, had only a modest effect on the particle size and shape, such that both rounded and facetted morphologies could be observed over a wide range of iron, base and nitrate concentrations (Figure S5b). The results obtained in the absence of nitrate (with polypeptides; Figure 6a, middle reaction set) were almost identical to the with-nitrate conditions (Figure 6a, leftmost reaction set), confirming that nitrate did not have a significant effect on the phase, size or shape of the mineral particles (Figures 6c-e). This 
showed that the nitrate ions were redundant under the selected reaction conditions and that the partial oxidation reaction depended on the presence of $\mathrm{O}_{2}$ only.

The results in this round therefore show that the polypeptides can induce magnetite formation under conditions where goethite would be the major product in their absence. The polypeptides are most effective in this role within a $\mathrm{pH}$ range of 12.8-13.1 and an $\mathrm{Fe}^{2+}$ concentration of 40$70 \mathrm{mM}$, and the $\mathrm{O}_{2}$ present in air is sufficient as an oxidant. Within this parameter space it is also possible to select magnetite crystals that are either larger and facetted or smaller and rounded according to the compositions of the polypeptides present.

\subsection{Assessment of Copolymer Activity}

Finally, a separate set of 96 experiments was conducted using the 7 EKA polymers from the third round to investigate the effect of the polypeptide compositions on the dimensions and morphologies of the magnetite crystals. The reactions were performed without $\mathrm{NO}_{3}{ }^{-}$but using ranges for $\mathrm{pH}(12.6-13.1)$ and $\mathrm{Fe}^{2+}$ concentration $(30-90 \mathrm{mM})$ that had produced magnetite in the presence of the polypeptides in all previous rounds. All reactions produced magnetite (Figure 7), but some goethite also formed under conditions with high $\mathrm{pH}(>12.9)$ and low $\mathrm{Fe}^{2+}$ concentrations $(30-50 \mathrm{mM})$. Control reactions performed without polypeptides also yielded magnetite (Figure S6) as is common in partial oxidation reactions using oxygen as the

oxidant, ${ }^{[16 b]}$ but magnetite formation occurred less reproducibly relative to reactions conducted with EKA polymer additives (Figure 7a vs. Figure S6).

Within this parameter space we identified a relatively narrow set of conditions $(\mathrm{pH}$ 12.9-13.1, $\left.\left[\mathrm{Fe}^{2+}\right]=50-70 \mathrm{mM}\right)$ where the control reactions generated large $(\approx 100 \mathrm{~nm})$ magnetite crystals in addition to other iron(hydr)oxide particles. Notably, the polypeptides had a significant effect 
on the size and shape of magnetite crystals under these conditions. This set of conditions was therefore selected to investigate the effects of the polypeptide composition alone on the size and shape of the magnetite crystals.

Low $[\mathrm{EKA}] /\left[\mathrm{Fe}^{2+}\right]$ ratios $(\approx 1 / 40)$ yielded $\approx 40 \mathrm{~nm}$ crystals with facetted morphologies with all of the polypeptides (Figure S7), where these crystals are much smaller than the magnetic particles formed in the copolymer-free controls (Figure 8). The crystals reduced in size on increase of the $[\mathrm{EKA}] /\left[\mathrm{Fe}^{2+}\right]$ ratios to $\approx 1 / 8($ Figures 8 and $\mathbf{S 8})$ and a clear dependency of their sizes and morphologies on the polypeptide compositions was also observed. While hydrophobic polypeptides with a high alanine (A) content generated larger, facetted crystals, hydrophilic polypeptides with a low alanine content yielded smaller, rounded crystals. The crystal size distributions ranged from $24 \pm 7 \mathrm{~nm}$ for $\mathbf{A 0 5}$ to $39 \pm 13 \mathrm{~nm}$ for A59, and in all cases the width of the size distribution relative to its mean $(\sigma / \mu)$ was $0.25-0.30$. No clear differences could be observed between experiments with polypeptides rich in glutamic acid (E) or lysine (K), which indicates that both glutamic acid and lysine are equally active, promoting the nucleation and inhibiting the growth of magnetite nanoparticles.

\section{Discussion}

While a number of studies have demonstrated that biomacromolecules provide promising control agents for in vitro magnetite synthesis, the mechanisms by which they operate are as yet poorly understood. ${ }^{[3 \mathrm{~b}, \mathrm{c}]}$ Most intensely investigated is Mms6, a magnetosome protein extracted from magnetotactic bacteria, which induces the formation of well-defined 20-30 nm magnetite crystals with a cubo-octahedral morphology. ${ }^{[22]}$ A number of us have also recently shown that the EKA polypeptides can be used to control the shape and size of magnetite precipitated in a ferrihydrite-based synthesis by binding $\mathrm{Fe}^{2+}$ and thereby changing the 
conditions under which nucleation occurs. Nucleation is either inhibited ${ }^{[10 \mathrm{~d}]}$ or the reaction pathway is changed, leading to a reduction in the polydispersity of the resulting crystal. ${ }^{[20]}$ Recently, the polyelectrolyte poly(aspartic acid) (pAsp), which is frequently used as a mimic of biomineralization proteins, was also shown to exert phase control over iron oxide by selecting ferrihydrite $\left(\mathrm{Fe}_{2} \mathrm{O}_{3} \cdot \mathrm{xH}_{2} \mathrm{O}\right)$ over lepidocrocite $(\gamma-\mathrm{FeOOH})$ during the synthesis of aqueous iron (oxyhydr)oxide using air as a $\mathrm{Fe}^{2+}$ oxidant. ${ }^{[23]}$

The genetic algorithm-guided combinatorial method described here allows us to explore a wide reaction landscape, and thus build a more comprehensive understanding of the activity of the EKA polypeptides in controlling magnetite precipitation. Our approach rapidly identified reaction conditions which yield ferrihydrite or goethite in the absence of these polypeptides, and phase pure magnetite crystals with relatively narrow size distributions in their presence. These aerobic solution conditions also reliably generate phase-pure, well-defined magnetite nanoparticles with no need for an additional oxidant. In contrast, the partial oxidation method using air often produces goethite $(\alpha-\mathrm{FeOOH})$ as a side product. ${ }^{[16 \mathrm{a}]}$

Most interestingly, the polypeptides drive the formation of magnetite under conditions where ferric (hydr)oxides would otherwise be formed. This can be attributed to binding of the $\mathrm{Fe}^{2+}$ ions by the polypeptides, which reduces the rate of oxidation and precludes over-oxidation. A 1:2 stoichiometric ratio of $\mathrm{Fe}^{2+}$ and $\mathrm{Fe}^{3+}$ is thus generated as required for the formation of magnetite. As such partial oxidation in the presence of oxygen occurs by initial oxidation of the surface of the $\mathrm{Fe}(\mathrm{OH})_{2}$ precursor, and its subsequent reaction with $\mathrm{Fe}(\mathrm{II})$ species in solution, ${ }^{[24]}$ we expect that the modulating effect of the polypeptides arises from their binding to the precursor surface.

Our experiments also demonstrate that the sizes and shapes of the magnetite crystals can be fine-tuned according to the compositions of the polypeptides. An increase in the fraction of hydrophilic amino acid residues $(\mathrm{E}$ and $\mathrm{K})$ produced smaller particles with rounded shapes. 
This indicates that these hydrophilic residues are active in controlling the growth of the nanoparticles, most likely through binding to the nanoparticle surface. ${ }^{[10 \mathrm{c}]}$ Little change in the size distribution of the crystals was observed according to the polypeptide compositions explored here, however, and although fairly uniform crystal populations were obtained, the relative widths of the size distributions $(\sigma / \mu)$ of the obtained nanoparticles seldom fell below $0.25-0.30$. Notably, both positively ${ }^{[10 b]}$ and negatively ${ }^{[9 c, 10 c]}$ charged biomacromolecular additives have previously been shown to yield narrow size dispersities between 0.14 and 0.26 . This suggests that the size distribution can be effectively controlled according to the structure of the additive, where our combinatorial screening platform would offer an attractive means of identifying potential candidates.

It is important to note that the combinatorial strategy employed here is essential to the efficient identification of $\mathrm{Fe}^{2+}$ concentrations and $\mathrm{pH}$ levels that provide optimal conditions for the polypeptides to direct the polymorph, size and shape of the magnetite nanocrystals. These two parameters alone influence a number of key aspects of this complex reaction system. For example, the $\mathrm{pH}$ not only determines the binding of the polymer to the mineral surface, but also the kinetics of magnetite formation, where the latter is determined by the rate of oxidation and the nature and concentrations of the Fe(II) species in solution. In turn, these are all influenced by the initial $\mathrm{Fe}^{2+}$ concentration and the amount of polymer present both in solution and on the mineral surface. Given the number of variables - and the fact that these are all subtly connected - this is clearly a system where identification of conditions that yield products with the target properties vastly benefits from an heuristic optimization such as the genetic algorithms employed here.

Finally, we draw attention to the fact that our genetic algorithm-led strategy in only three screening rounds has led to the successful identification of reaction conditions that generate magnetite nanoparticles with a narrow size distribution $(\sigma / \mu=0.3)$ and diameters ranging from 
25-40 $\mathrm{nm}$ (i.e., in the single domain range) in a simple room temperature, aqueous synthesis, performed under aerobic conditions. Currently, most synthetic magnetite is produced through the coprecipitation of $\mathrm{Fe}^{2+}$ and $\mathrm{Fe}^{3+}$ at high $\mathrm{pH}$ (the Massart reaction ${ }^{[18 \mathrm{~b}]}$ ), which owes its popularity to its experimental simplicity. However, the magnetite nanoparticles generated are polydisperse, and superparamagnetic, with diameters of $<20 \mathrm{~nm}$. Simple aqueous procedures yielding single domain magnetite particles have been described ${ }^{[24]}$ but again yield a wide distribution of particle sizes. To generate single domain magnetite with narrow size distributions requires the stringent exclusion of oxygen ${ }^{[10 \mathrm{c}]}$ and often also elevated temperatures have been required. ${ }^{[16]}$

Similar to what we demonstrated in previous studies, we expect that the interactions of the polypeptides with the magnetite surface will allow the generation of dispersible, colloidal stable single domain magnetic nanoparticles ${ }^{[10 \mathrm{~d}]}$ that may find possible applications in separation technology or magnetic resonance imaging. Although we used polypeptides to mediate magnetite formation here, we strongly believe that similar results can be obtained by more common readily available polymers such as acrylate copolymers from different anionic, cationic and hydrophobic monomers. Indeed, the experimental approach described here is ideally suited to the identification of additives - or combinations of additives - that can control magnetite precipitation in aqueous conditions. 


\section{Conclusion}

This work describes how combinatorial processes, guided by genetic algorithms, provide a unique means to investigate, and optimize bio-inspired mineralization strategies. Addressing the complex process of copolymer-directed magnetite formation we show that this evolutionary strategy can be used to simultaneously optimize the phase purity, size distribution and morphology of magnetite crystals. This approach has proven particularly valuable in the investigated mineralization system, where the precipitation of iron oxyhydr(oxide) is extremely sensitive to the solution conditions and we are evaluating a diverse set of structurally-distinct polypeptides. Our combinatorial screening process shows that polypeptide additives can promote magnetite formation under reaction conditions where this phase is normally not formed (instead goethite is obtained), and we demonstrate that the [polypeptide] / $\left[\mathrm{Fe}^{2+}\right]$ ratio and the polypeptide compositions both control the sizes and shapes of the magnetite crystals. The hydrophilic residues in the polypeptides promote magnetite nucleation and the products can be tuned within the ferrimagnetic single domain size regime from $\approx 25 \mathrm{~nm}$ (rounded particles) to $\approx 40 \mathrm{~nm}$ (facetted crystals) by increasing the fraction of hydrophobic amino acids. This control over nanoparticle size is directly coupled to the magnetic properties of these magnetite nanocrystals. The methodologies presented here therefore open the door to further optimization of the synthesis of magnetite, and indeed a wide range of functional materials produced in aqueous medium.

\section{Supporting Information}

Supporting Information is available from the Wiley Online Library or from the author.

\section{Acknowledgements}


This work was supported by an Engineering and Physical Sciences Research Council (EPSRC) Leadership Fellowship (FCM and LAB, EP/H005374/1), and also an EPSRC Programme Grant (grant EP/I001514/1) which funds the Materials Interface with Biology (MIB) consortium (FCM and DCG). The work of J.J.M.L. was supported by NanoNextNL, a micro and nanotechnology consortium of the government of The Netherlands and 130 partners, while the work of N.A.J.M.S. and P.H.H.B. was supported by a VICI grant of the Dutch Science Foundation - Chemical Sciences (NWO-CW). H.R.Z. and A.K. acknowledge the support of the European Research Council via an ERC starting grant (Project No. 240394). The authors would like to thank Dr Christopher J. Empson (School of Chemistry, University of Leeds) for his assistance with the liquid handling robot experiments.

Received: ((will be filled in by the editorial staff)) Revised: ((will be filled in by the editorial staff)) Published online: ((will be filled in by the editorial staff)) 


\section{References}

[1] a) D. Faivre and D. Schüler, Chemical Reviews 2008, 108, 4875-4898; b) D. Faivre and T.

U. Godec, Angewandte Chemie International Edition 2015, 54, 4728-4747.

[2] a) A. Komeili, Annual Review of Biochemistry 2007, 76, 351-366; b) D. Schüler, FEMS Microbiology Reviews 2008, 32, 654-672.

[3] a) T. Prozorov, D. A. Bazylinski, S. K. Mallapragada and R. Prozorov, Materials Science and Engineering R: Reports 2013, 74, 133-172; b) G. Mirabello, J. J. M. Lenders and N. A. J. M. Sommerdijk, Chemical Society Reviews 2016, 45, 5085-5106; c) J. J. M. Lenders, G.

Mirabello and N. A. J. M. Sommerdijk, Chemical Science 2016, 7, 5624-5634.

[4] F. Nudelman and N. A. J. M. Sommerdijk, Angewandte Chemie-International Edition 2012, 51, 6582-6596.

[5] a) K. Grünberg, C. Wawer, B. M. Tebo and D. Schüler, Applied and Environmental Microbiology 2001, 67, 4573-4582; b) S. Schübbe, M. Kube, A. Scheffel, C. Wawer, U. Heyen, A. Meyerdierks, M. H. Madkour, F. Mayer, R. Reinhardt and D. Schüler, Journal of Bacteriology 2003, 185, 5779-5790; c) S. Ullrich, M. Kube, S. Schübbe, R. Reinhardt and D. Schüler, Journal of Bacteriology 2005, 187, 7176-7184.

[6] R. M. Cornell and U. Schwertmann, The Iron Oxides: Structure, Properties, Reactions, Occurrences and Uses, Wiley-VCH, Weinheim, 2003, p.

[7] a) R. S. Sapieszko and E. Matijević, Journal of Colloid and Interface Science 1980, 74, 405-422; b) X. Wang, J. Zhuang, Q. Peng and Y. Li, Nature 2005, 437, 121-124; c) X. Sun, C. Zheng, F. Zhang, Y. Yang, G. Wu, A. Yu and N. Guan, The Journal of Physical Chemistry C 2009, 113, 16002-16008.

[8] a) S. Sun and H. Zeng, Journal of the American Chemical Society 2002, 124, 8204-8205;

b) J. Park, K. An, Y. Hwang, J.-G. Park, H.-J. Noh, J.-Y. Kim, J.-H. Park, N.-M. Hwang and 
T. Hyeon, Nature Materials 2004, 3, 891-895; c) T. Hyeon, S. S. Lee, J. Park, Y. Chung and H. B. Na, Journal of the American Chemical Society 2001, 123, 12798-12801.

[9] a) T. Prozorov, S. K. Mallapragada, B. Narasimhan, L. Wang, P. Palo, M. NilsenHamilton, T. J. Williams, D. A. Bazylinski, R. Prozorov and P. C. Canfield, Advanced Functional Materials 2007, 17, 951-957; b) J. Baumgartner, A. Dey, P. H. H. Bomans, C. Le Coadou, P. Fratzl, N. A. J. M. Sommerdijk and D. Faivre, Nature Materials 2013, 12, 310314; c) J. J. M. Lenders, C. L. Altan, P. H. H. Bomans, A. Arakaki, S. Bucak, G. de With and N. A. J. M. Sommerdijk, Crystal Growth \& Design 2014, 14, 5561-5568.

[10] a) A. Arakaki, F. Masuda, Y. Amemiya, T. Tanaka and T. Matsunaga, Journal of Colloid and Interface Science 2010, 343, 65-70; b) J. Baumgartner, M. Antonietta Carillo, K. M. Eckes, P. Werner and D. Faivre, Langmuir 2014, 30, 2129-2136; c) C. L. Altan, J. J. M. Lenders, P. H. H. Bomans, G. de With, H. Friedrich, S. Bucak and N. A. J. M. Sommerdijk, Chemistry - A European Journal 2015, 21, 6150-6156; d) J. J. M. Lenders, H. R. Zope, A. Yamagishi, P. H. H. Bomans, A. Arakaki, A. Kros, G. de With and N. A. J. M. Sommerdijk, Advanced Functional Materials 2015, 25, 711-719.

[11] L. Davis, Handbook of Genetic Algorithms, Van Nostrand Reinhold, New York, 1991, p. [12] a) H. Koinuma and I. Takeuchi, Nature Materials 2004, 3, 429-438; b) R. Hoogenboom, M. A. R. Meier and U. S. Schubert, Macromolecular Rapid Communications 2003, 24, 15-32. [13] a) J. Devillers, Genetic Algorithms in Molecular Modeling, Academic Press, London, 1996, p; b) G. Schneider and U. Fechner, Nature Reviews Drug Discovery 2005, 4, 649-663. [14] a) W. F. Maier, K. Stöwe and S. Sieg, Angewandte Chemie International Edition 2007, 46, 6016-6067; b) R. Potyrailo, K. Rajan, K. Stoewe, I. Takeuchi, B. Chisholm and H. Lam, ACS Combinatorial Science 2011, 13, 579-633; c) A. K. Sharma, K. H. Son, B. Y. Han and K.-S. Sohn, Advanced Functional Materials 2010, 20, 1750-1755; d) L. A. Bawazer, M. Izumi, D. Kolodin, J. R. Neilson, B. Schwenzer and D. E. Morse, Proceedings of the National 
Academy of Sciences 2012, 109, E1705-E1714; e) J. Kohn, Nature Materials 2004, 3, 745747.

[15] L. A. Bawazer, J. Ihli, T. P. Comyn, K. Critchley, C. J. Empson and F. C. Meldrum, Advanced Materials 2014, 27, 223-227.

[16] a) T. Sugimoto and E. Matijević, Journal of Colloid and Interface Science 1980, 74, 227-

243; b) F. Vereda, J. de Vicente and R. Hidalgo-Alvarez, Journal of Colloid and Interface Science 2013, 392, 50-56.

[17] a) C. Domingo, R. Rodríguez-Clemente and M. A. Blesa, Colloids and Surfaces A: Physicochemical and Engineering Aspects 1993, 79, 177-189; b) F. Vereda, J. de Vicente and R. Hidalgo-Alvarez, Journal of Colloid and Interface Science 2013, 392, 50-56; c) Z. Li, M. Kawashita, N. Araki, M. Mitsumori, M. Hiraoka and M. Doi, Journal of Biomaterials Applications 2011, 25, 643-661; d) K. Nishio, M. Ikeda, N. Gokon, S. Tsubouchi, H. Narimatsu, Y. Mochizuki, S. Sakamoto, A. Sandhu, M. Abe and H. Handa, Journal of Magnetism and Magnetic Materials 2007, 310, 2408-2410.

[18] a) M. Kiyama, Bulletin of the Institute for Chemical Research, Kyoto University 1970, 47, 607-612; b) R. Massart, IEEE Transactions on Magnetics 1981, 17, 1247-1248; c) A.-H. Lu, E. L. Salabas and F. Schüth, Angewandte Chemie International Edition 2007, 46, 12221244; d) S. Laurent, D. Forge, M. Port, A. Roch, C. Robic, L. Vander Elst and R. N. Muller, Chemical Reviews 2008, 108, 2064-2110; e) T. Ahn, J. H. Kim, H.-M. Yang, J. W. Lee and J.-D. Kim, The Journal of Physical Chemistry C 2012, 116, 6069-6076.

[19] V. Dmitrović, J. J. M. Lenders, H. R. Zope, G. de With, A. Kros and N. A. J. M. Sommerdijk, Biomacromolecules 2014, 15, 3687-3695.

[20] A. Dey, J. J. M. Lenders and N. A. J. M. Sommerdijk, Faraday Discussions 2015, 179, 215-225.

[21] P. Refait and J. M. R. Genin, Corrosion Science 1993, 34, 797-819. 
[22] a) Y. Amemiya, A. Arakaki, S. S. Staniland, T. Tanaka and T. Matsunaga, Biomaterials

2007, 28, 5381-5389; b) S. S. Staniland and A. E. Rawlings, Biochemical Society

Transactions 2016, 44, 883-890.

[23] L. M. Gordon, J. K. Román, R. M. Everly, M. J. Cohen, J. J. Wilker and D. Joester, Angewandte Chemie International Edition 2014, 53, 11506-11509.

[24] Y. Tamaura, P. V. Buduan and T. Katsura, Journal of the Chemical Society-Dalton Transactions 1981, 1807-1811. 

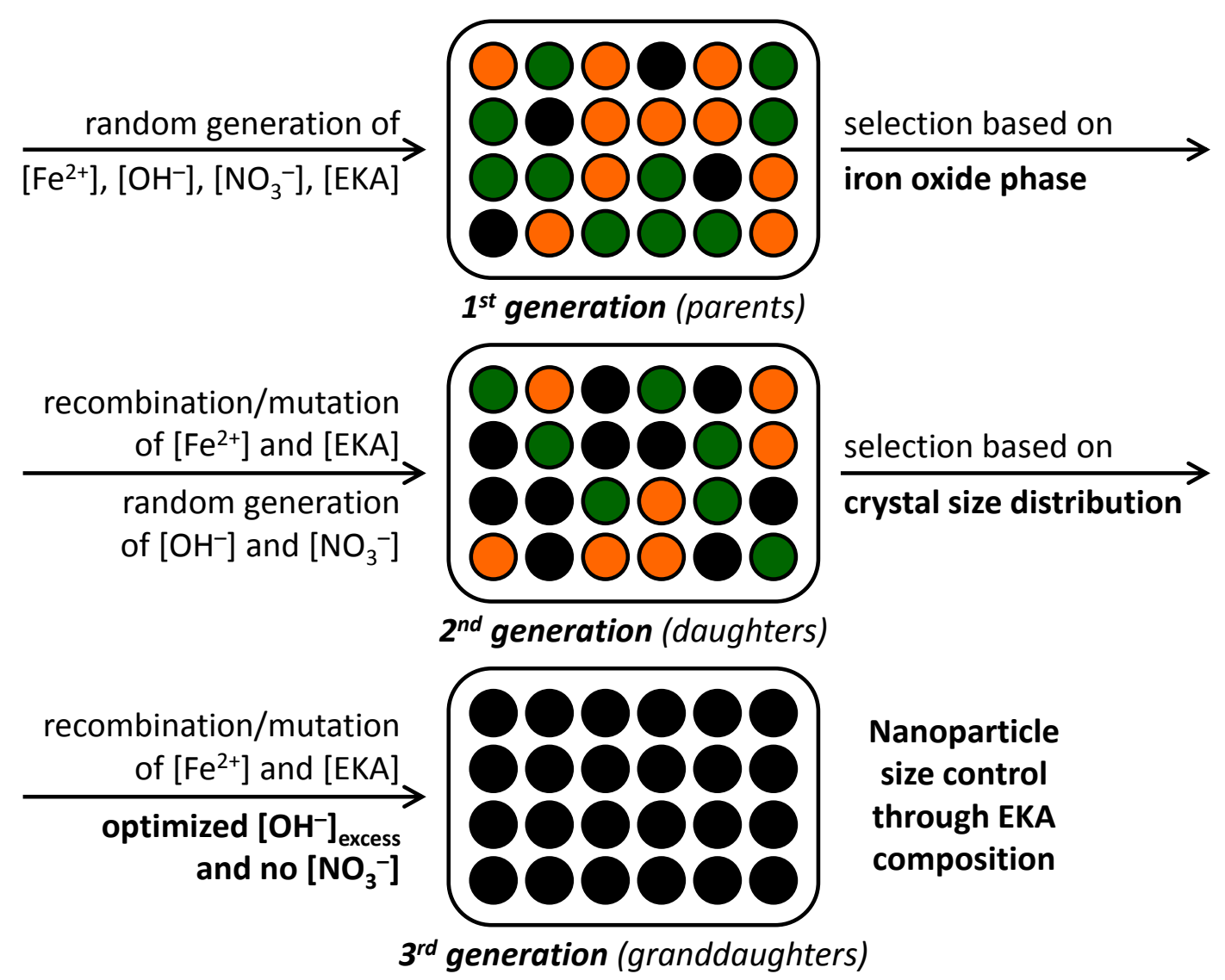

Figure 1. Overview of the genetic optimization strategy employed in this study. Random generation of reactant concentrations ("genes") and subsequent selection, recombination and mutation of those genes leads to successful magnetite synthesis, where the phase purity and size distributions of the nanoparticles could be genetically optimized over three generations of experiments. See the text for more details. 


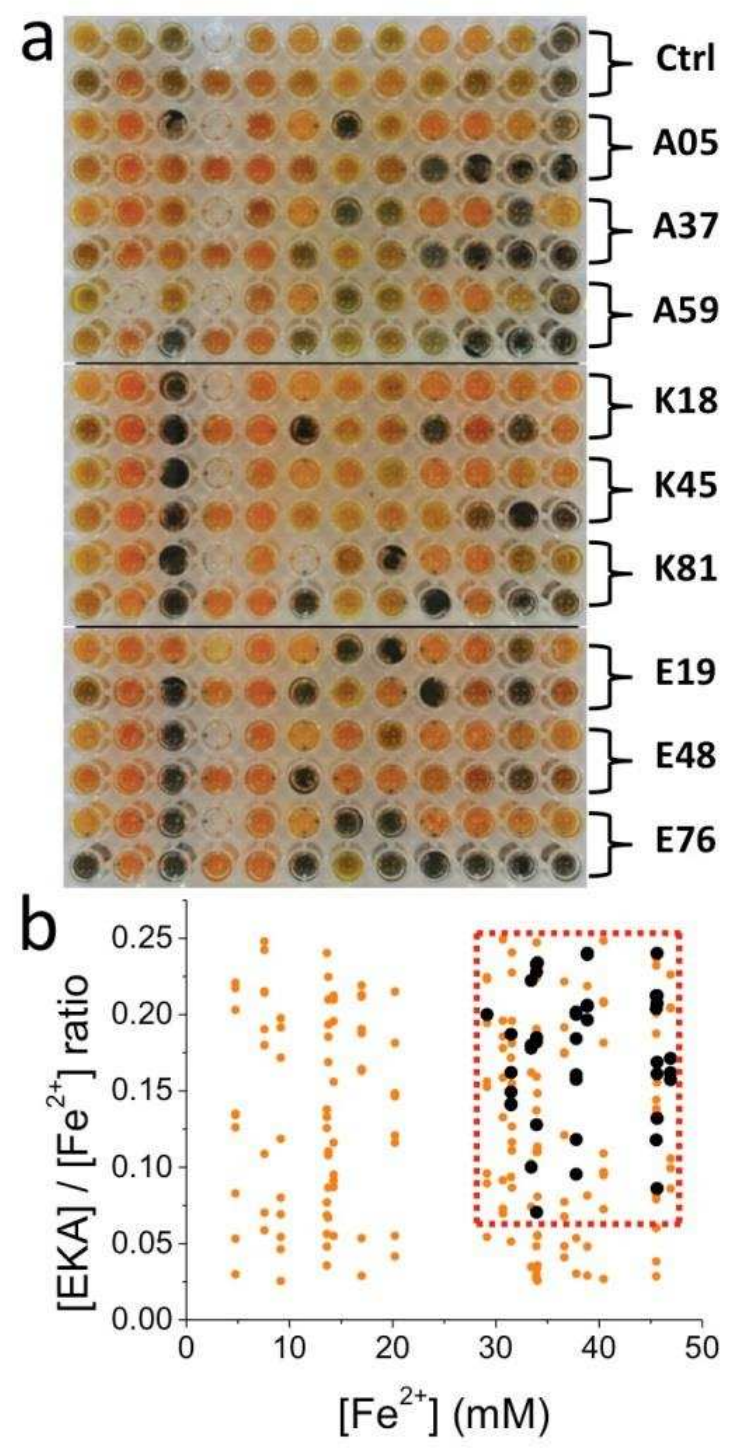

Figure 2. First generation screening. a) Pictures of the three 96-well plates containing the products of the 240 first generation (parent) experiments without ( $\mathrm{Ctrl}$, no magnetite formation) and with the 9 different EKA additives (see Table 1). A black precipitate color combined with responsiveness of the precipitate to a magnet was used as a proxy for successful conversion to magnetite, where this was confirmed to have taken place in 42 of the 216 experiments (19\%) with EKA additives. b) Scatter plot of the randomly generated $\mathrm{Fe}^{2+}$ concentrations and $[\mathrm{EKA}] /\left[\mathrm{Fe}^{2+}\right]$ ratios for the 216 experiments. Black dots represent successful conversion to magnetite, orange dots represent unsuccessful conversion, where other iron (oxyhydr)oxides were produced instead. 


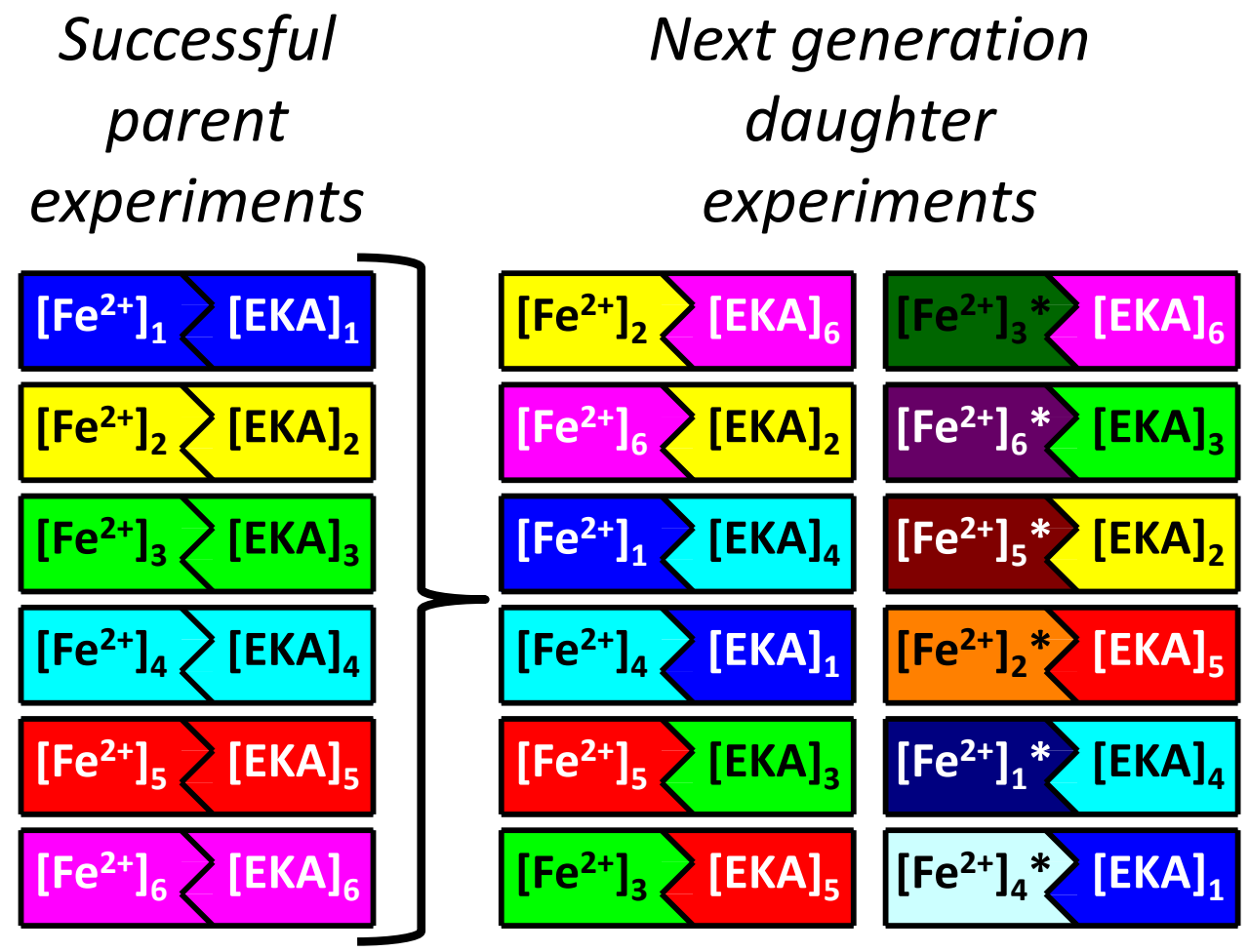

Figure 3. Scheme visualizing the concept of the use of genetic algorithms by generation of 12 new daughter experiments out of 6 successful parent experiments (1-6). The process involves the random selection of 2 parent experiments and the recombination of their $\left[\mathrm{Fe}^{2+}\right]$ and $[\mathrm{EKA}]$ genes to create 2 daughter experiments. Once a $\left[\mathrm{Fe}^{2+}\right]$ gene is selected for the second time, it is randomly mutated (indicated by an asterisk (*) and a color shift) to avoid duplicate daughter experiments. The 6 parent experiments and 12 daughter experiments are subsets of the 42 / 11 parent experiments and 96 / 32 daughter experiments in optimization rounds 2 / 3 , respectively. 

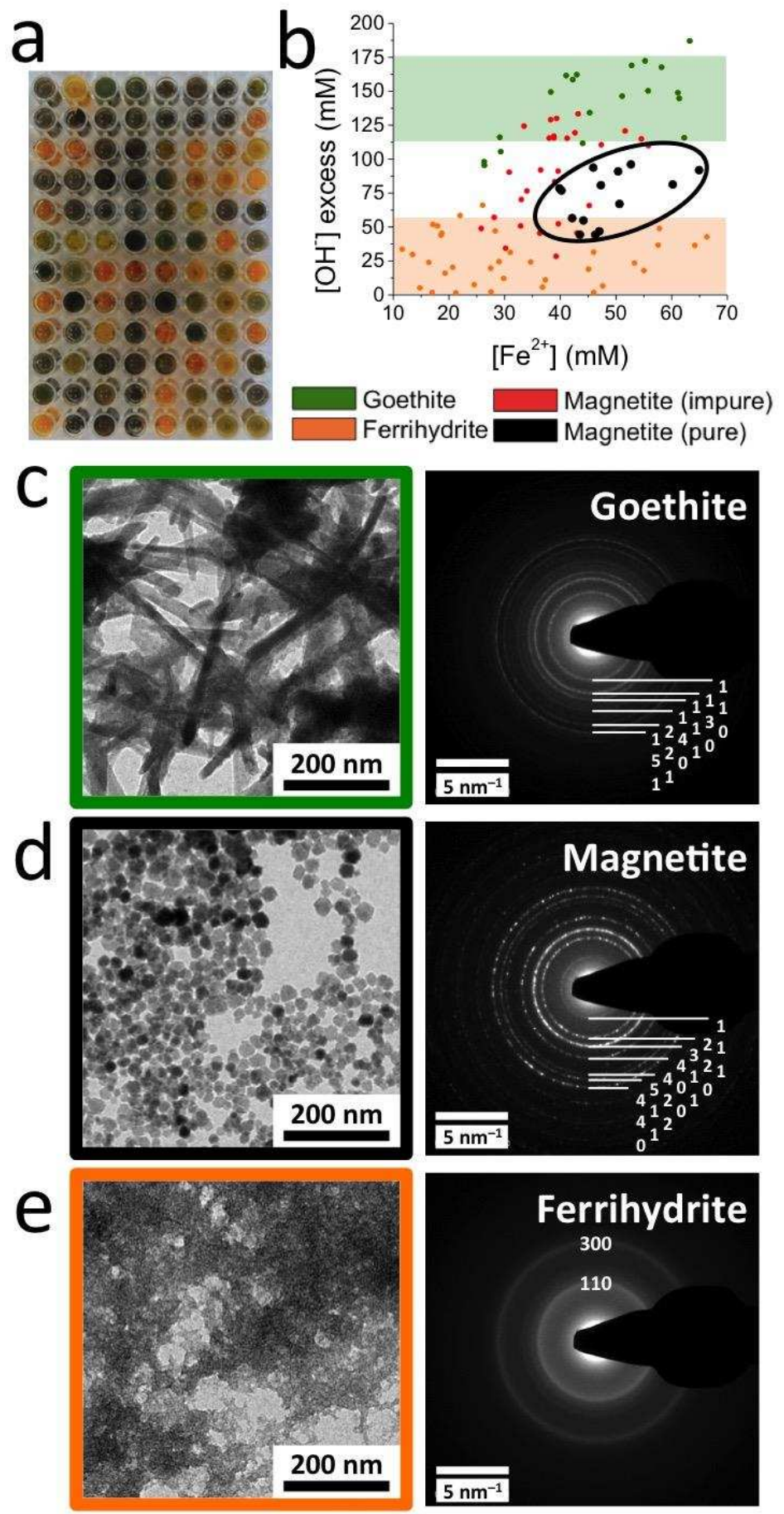

Figure 4. Second generation screening. a) Picture of the 96-well plate containing the products of the 96 second generation experiments. A black color with a magnetic response indicates successful conversion to magnetite in 42 of the 96 experiments (44\%). b) Scatter plot of the genetically optimized $\mathrm{Fe}^{2+}$ concentrations and $\left[\mathrm{OH}^{-}\right]_{\text {excess }}$ for the 96 experiments. c-e) Representative TEM images with corresponding SAED patterns of c) goethite, d) magnetite and e) ferrihydrite. The colors correspond to those in b). 

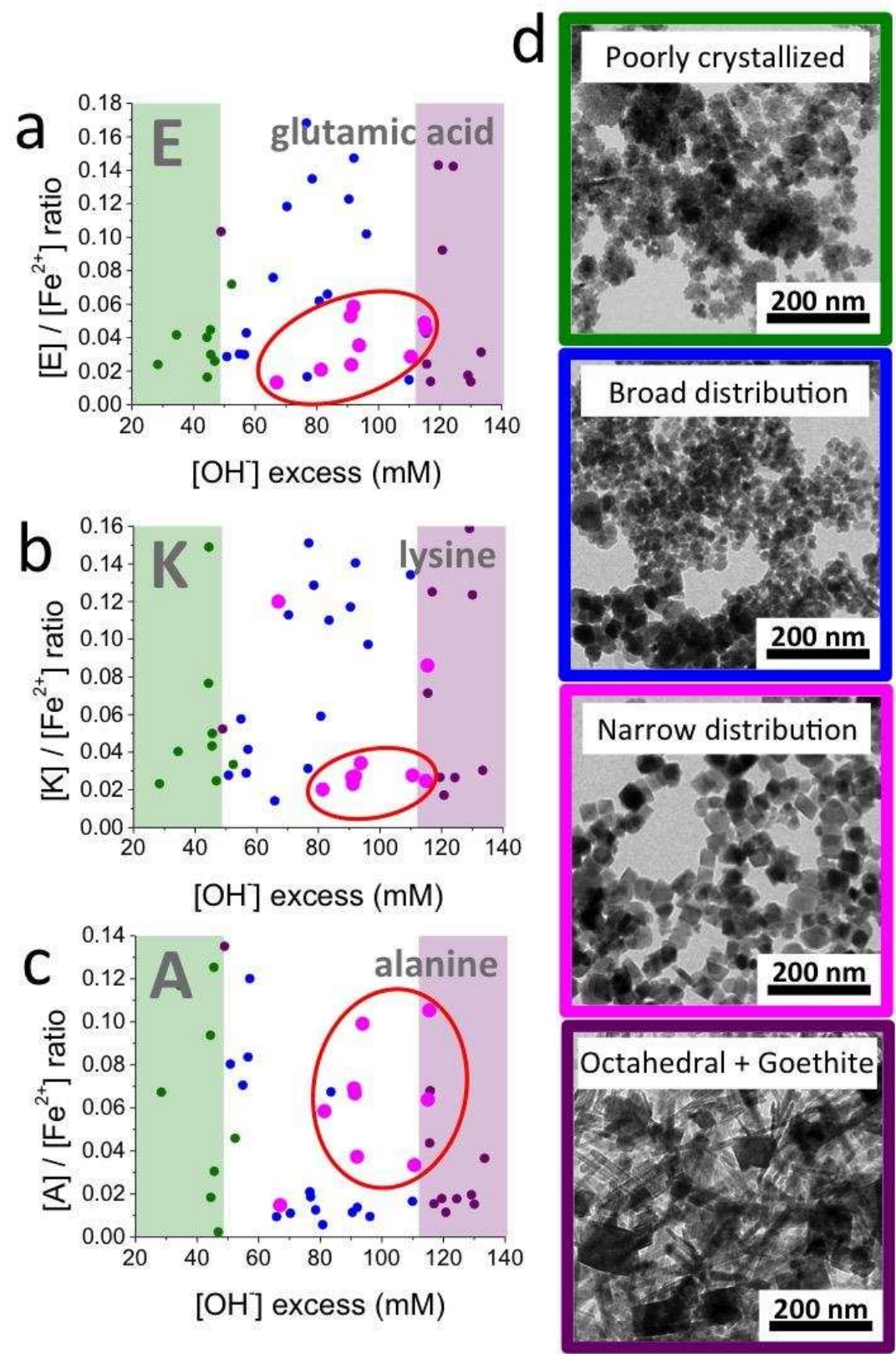

Figure 5. Second generation screening. a-c) Scatter plots of the a) $[\mathrm{E}] /\left[\mathrm{Fe}^{2+}\right]$ ratio, b) $[\mathrm{K}] /$ $\left[\mathrm{Fe}^{2+}\right]$ ratio and c) $[\mathrm{A}] /\left[\mathrm{Fe}^{2+}\right]$ ratio plotted against $[\mathrm{OH}-]$ excess for the 42 successful second generation experiments. d) Representative TEM images of (left to right) poorly crystallized magnetite, magnetite with a broad size distribution, magnetite with a narrow size distribution and octahedral magnetite crystals mixed with goethite needles. The colors of the picture borders correspond to those of the dots in a-c). 


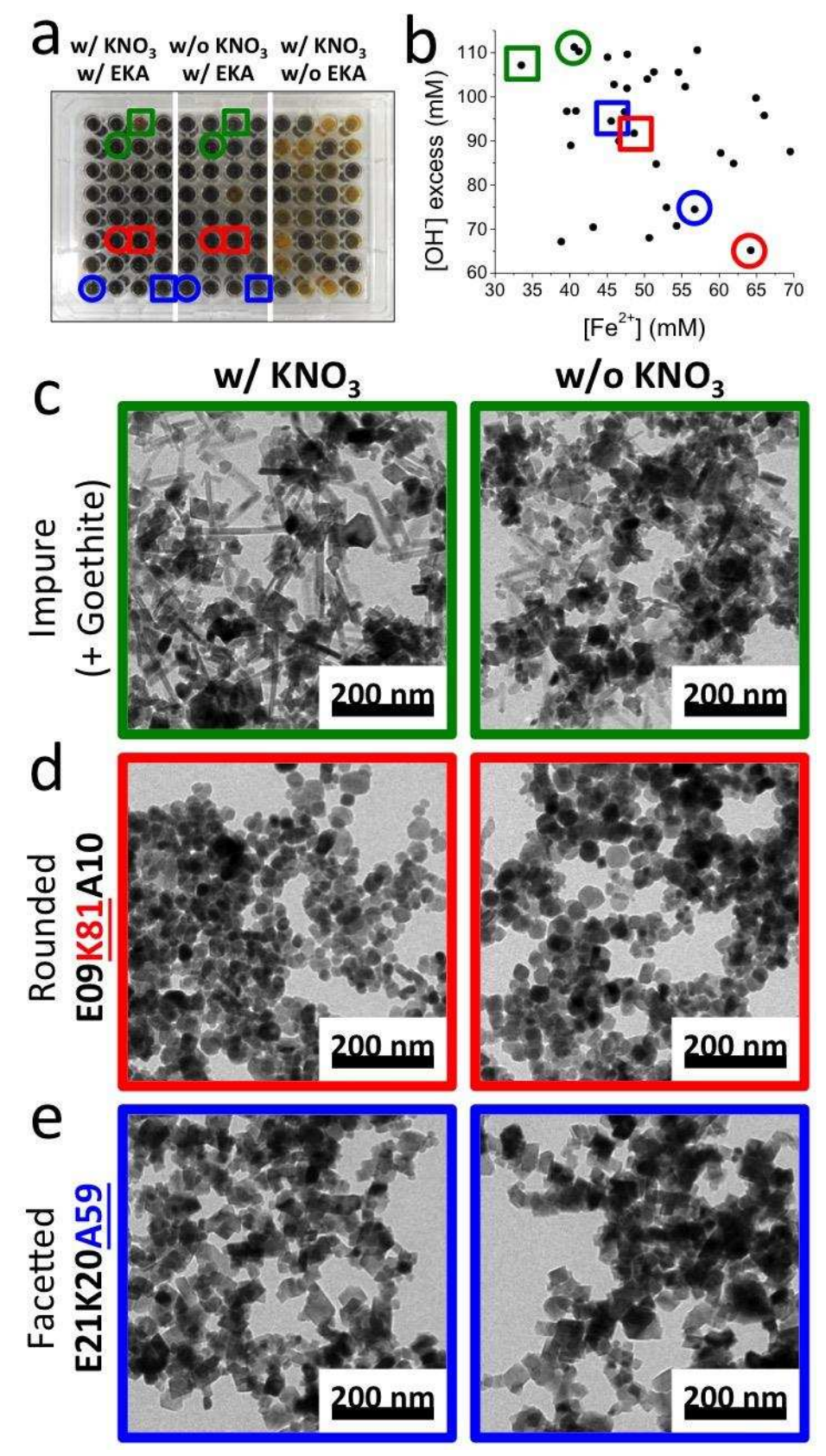

Figure 6. Third generation screening. a) Picture of the 96-well plate containing the products of the $3 \times 32$ third generation, with $(\mathrm{w} /)$ or without (w/o) oxidant $\left(\mathrm{KNO}_{3}\right)$ or additives (EKA). b) Scatter plot of the genetically optimized $\mathrm{Fe}^{2+}$ concentrations and $\left[\mathrm{OH}^{-}\right]$excess for the $3 \times$ 32 experiments. The circles and squares indicate for selected experiments which wells correspond to which reactant concentrations. c-e) Representative TEM images of the selected experiments with (w/) or without (w/o) oxidant $\left(\mathrm{KNO}_{3}\right)$. The colors correspond to those in a) and $b)$. 

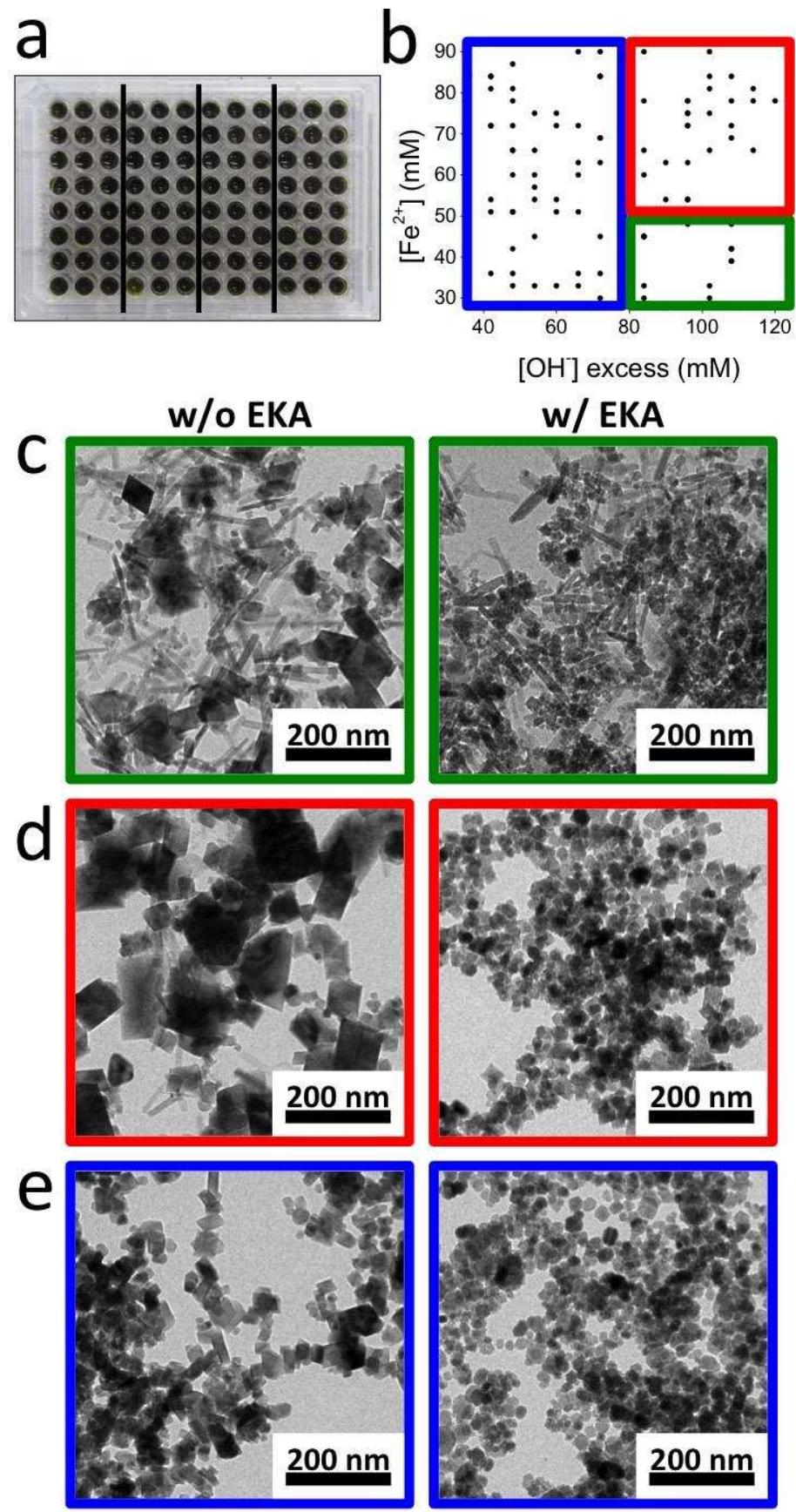

Figure 7. Additional experiments using the conditions that previously successfully gave magnetite $\left(30 \mathrm{mM}<\left[\mathrm{Fe}^{2+}\right]<90 \mathrm{mM}, 40 \mathrm{mM}<\left[\mathrm{OH}^{-}\right]\right.$excess $\left.<120 \mathrm{mM}\right)$. a) Picture of the 96well plate containing the products of 32 out of the 96 additional experiments, all repeated 3 times, showing good reproducibility. b) Scatter plot of the reactant concentrations of the 96 additional experiments: $\left[\mathrm{Fe}^{2+}\right]$ plotted against $\left[\mathrm{OH}^{-}\right]$excess. c) Typical TEM images of the magnetite products obtained without (w/o) or with (w/) additives in different areas in the parameter space. The color codes correspond to those in b). 
Figure 8. Typical TEM images of magnetite products in the $50-70 \mathrm{mM}\left[\mathrm{Fe}^{2+}\right] / 80-120 \mathrm{mM}$ $\left[\mathrm{OH}^{-}\right]$excess parameter space without (Control) or with various EKA additives at a [EKA] / $\left[\mathrm{Fe}^{2+}\right]$ ratio of $\sim 1 / 8$, showing a trend from smaller $(\sim 24 \mathrm{~nm})$, rounded particles to larger $(\sim 39$ $\mathrm{nm}$ ), facetted crystals, depending on the A content of the copolypeptides. Statistical analyses showed that the increases in mean particle size between the different samples are significant (see the caption of Figure S8 in the supporting information).

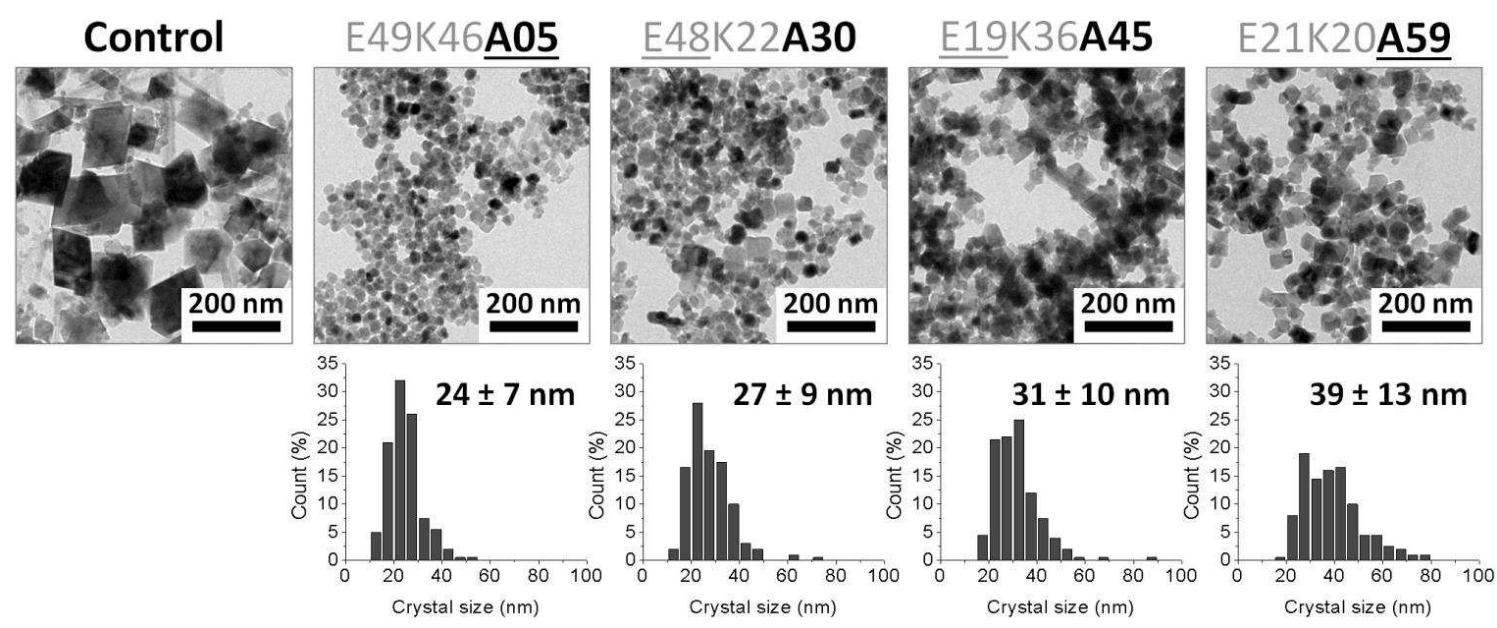


Table 1. Overview of all random polypeptide additives applied in this study, the sample codes used for reference and their amino acid compositions.

\begin{tabular}{ll}
\hline Sample code & Amino acid composition [mol\%] ${ }^{\text {a }}$ \\
\hline E19 & {$[E] 19 \%[K] 36 \%[A] 45 \%$} \\
E48 & {$[E] 48 \%[K] 22 \%[A] 30 \%$} \\
E76 & {$[E] 76 \%[K] 14 \%[A] 10 \%$} \\
K18 & {$[E] 36 \%[K] 18 \%[A] 46 \%$} \\
K45 & {$[E] 27 \%[K] 45 \%[A] 28 \%$} \\
K81 & {$[E] 09 \%[K] 81 \%[A] 10 \%$} \\
A05 & {$[E] 49 \%[K] 46 \%[A] 05 \%$} \\
A37 & {$[E] 32 \%[K] 31 \%[A] 37 \%$} \\
A59 & {$[E] 21 \%[K] 20 \%[A] 59 \%$}
\end{tabular}

${ }^{\text {a) }}$ Determined from ${ }^{1} \mathrm{H}$ NMR data. ${ }^{[19]}$ 


\section{Supporting Information}

\section{Combinatorial Evolution of Biomimetic Magnetite Nanoparticles}

Jos J.M. Lenders ${ }^{\mathrm{a}, \mathrm{b}}$, Lukmaan A. Bawazer ${ }^{\mathrm{c}}$, David C. Green ${ }^{\mathrm{c}}$, Harshal R. Zope ${ }^{\mathrm{d \#}}$, Paul H.H. Bomans $^{\mathrm{a}, \mathrm{b}}$, Gijsbertus de With ${ }^{\mathrm{a}}$, Alexander $\mathrm{Kros}^{\mathrm{d}}$, Fiona C. Meldrum, ${ }^{\mathrm{c},}$, and Nico A.J.M. Sommerdijk $\mathrm{a}^{\mathrm{a}, \mathrm{b}^{*}}$

Dr. Jos J.M. Lenders, Dr. Paul H.H. Bomans, Prof. Dr. Gijsbertus de With, Prof. Dr. Nico A.J.M. Sommerdijk* Laboratory of Materials and Interface Chemistry and Center of Multiscale Electron Microscopy, Department of Chemical Engineering and Chemistry, Eindhoven University of Technology, P.O. Box 513, 5600 MB Eindhoven, The Netherlands

E-mail: n.sommerdijk@tue.nl

Dr. Jos J.M. Lenders, Paul H.H. Bomans Prof. Dr. Nico A.J.M. Sommerdijk Institute for Complex Molecular Systems, Eindhoven University of Technology, P.O. Box 513, 5600 MB Eindhoven, The Netherlands

Dr. Lukmaan A. Bawazer, Dr. David C. Green, Prof. Fiona Meldrum*

School of Chemistry, University of Leeds, Woodhouse Lane, Leeds LS2 9JT, United Kingdom

E-mail: f.meldrum@ leeds.ac.uk

Dr. Harshal R. Zope, Prof. Alexander Kros

Leiden Institute of Chemistry, Leiden University, P.O. Box 9502, 2300 RA Leiden, The Netherlands

\$ Present address: Department of Bioengineering, Stanford University, 443 Via Ortega, Stanford, CA 94304, United States of America;

\# Present address: Laboratory of Nanomedicine and Biomaterials and Brigham and Women's Hospital, Harvard Medical School", 75 Francis Street, Boston, MA 02115, United States of America 


\section{Materials and Methods}

\section{$\underline{\text { Chemicals }}$}

All experiments involved ultrapure water (resistivity $18.2 \mathrm{M} \Omega \cdot \mathrm{cm}$ at $20^{\circ} \mathrm{C}$ ) which was deaerated using a $\mathrm{N}_{2}$ flow for at least 30 min prior to use. $\mathrm{FeCl}_{2} \cdot 4 \mathrm{H}_{2} \mathrm{O}, \mathrm{KOH}$ and $\mathrm{KNO}_{3}$ were purchased from Merck. All chemicals were used as received. The random amino acid copolymer additives were synthesized and analyzed as described in an earlier publication.*

* V. Dmitrović, J.J.M. Lenders, H.R. Zope, G. de With, A. Kros and N.A.J.M. Sommerdijk, “Library of Random Copolypeptides by Solid Phase Synthesis”, Biomacromolecules 2014, 15 (10), 3687-3695.

\section{$\underline{\text { Combinatorial screening experiments }}$}

All reactions were performed on a $200 \mu \mathrm{L}$ scale with the aid of a Hamilton Microlab STAR liquid handling pipetting workstation, and GreinerTM $\mu$ Clear flat-bottomed 96 well plates, (clear), assigning a maximum volume of $50 \mu \mathrm{L}$ for each of the stock solutions of $\mathrm{FeCl}_{2}, \mathrm{KOH}$, $\mathrm{KNO}_{3}$ and amino acid copolymers, while in all cases the reaction volume was set to $200 \mu \mathrm{L}$ by the addition of pure water. Further, the lower boundary conditions for the base and the oxidant were set to $\left[\mathrm{OH}^{-}\right]=2\left[\mathrm{Fe}^{2+}\right]$ and $\left[\mathrm{NO}_{3}^{-}\right]=1 / 3\left[\mathrm{Fe}^{2+}\right]$ to ensure that the experiments exclusively sampled conditions with an excess of base and oxidant. The freshly prepared $\mathrm{FeCl}_{2}$ stock solution was always added to the $\mathrm{KOH} / \mathrm{KNO}_{3}$ / additive / water mixtures as the final step to avoid premature oxidation. Subsequently, the 96-well plate was closed by a sealing mat and vigorously mixed over night at $1200 \mathrm{rpm}$ using a mechanical shaking device to homogenize the reaction mixture and allow the partial oxidation to be completed. Identification of conversion 
to magnetite was initially performed by inspection of the color and magnetic response to a handheld neodymium disc magnet.

For the preparation of the first generation of samples the following procedure was used:

Aqueous stock solutions were prepared in volumetic flasks immediately before use. Stocks of potassium hydroxide (1.2 M, $1.6833 \mathrm{~g}$ in $25 \mathrm{~mL}$ de-aerated water) and potassium nitrate (200 $\mathrm{mM}, 0.5055 \mathrm{~g}$ in $25 \mathrm{~mL}$ de-aerated water) were used as prepared. Stock solution of iron (ii) chloride $(0.63375 \mathrm{~g}$ in $25 \mathrm{~mL}$ de-aerated water $)$ was filtered through a syringe-driven $0.22 \mu \mathrm{m}$ polycarbonate filter prior to use to remove trace insoluble particles to yield a clear, green solution. Each EKA polypeptide was prepared in a $7 \mathrm{~mL}$ glass vial to the predetermined final concentration with de-aerated water. Using the liquid-handling pipetting workstation, specific volumes of de-aerated water; and potassium hydroxide, potassium nitrate and EKA polypeptide stock solutions were mixed in the 96-well plates, before the addition of iron (ii) chloride solution to initiate the reaction, make up each reagent to the final desired concentration and a final volume of $200 \mu \mathrm{L}$. Potassium hydroxide, potassium nitrate and iron (ii) chloride salts were added from $120 \mathrm{~mL}$ troughs using $300 \mu \mathrm{L}$ pipette tips to ensure rapid transfer of larger volumes $(>50 \mu \mathrm{L})$. EKA polypeptides were added from $8 \mathrm{~mL}$ barcoded stock glass vials using $50 \mu \mathrm{L}$ to ensure higher accuracy due to lower volumes required. Well plates were immediately sealed after the final additions were made using well plate sealing mats (Corning) before vigorous mixing at $1200 \mathrm{rpm}$ using a mechanical shaker for $16 \mathrm{~h}$.

Similar procedures were used for the follow-up reactions.

\section{$\underline{\text { Transmission electron microscopy (TEM) }}$}

For conventional TEM, 200 mesh Cu grids with continuous carbon films (Agar Scientific) were used. All TEM grids were surface plasma treated for 40 seconds using a Cressington 208 carbon coater prior to use. Sample preparation involved dropping $3 \mu \mathrm{L}$ aqueous dispersion onto a TEM 
grid, blotting using filter paper and allowing the grid to dry to the air. TEM samples were studied on a FEI Tecnai 20 (type Sphera) operated at $200 \mathrm{kV}$, equipped with a $\mathrm{LaB}_{6}$ filament and a $1 \mathrm{k} \times 1 \mathrm{k}$ Gatan CCD camera. Gatan DigitalMicrograph (including DiffTools) and ImageJ were used for TEM image and SAED pattern analysis.

\section{$\underline{\text { Crystal size measurements }}$}

Crystal size distributions were determined by manually measuring both the long and short axis of 200 individual crystals per sample in calibrated TEM images in MATLAB. The average of the long and short axis per crystal was taken as the crystal size. Crystal sizes are reported as mean \pm sample standard deviation. In all statistical tests an alpha value of 0.05 was used (95\% confidence level). Prior to all t-tests, one-tailed F-tests were carried out to determine whether the variances in the two crystal size distributions under investigation should be treated as equal or unequal. For all t-tests, the determined t value was compared to the two-tailed critical $t$ value, and the corresponding two-tailed $\mathrm{p}$ value is reported. 

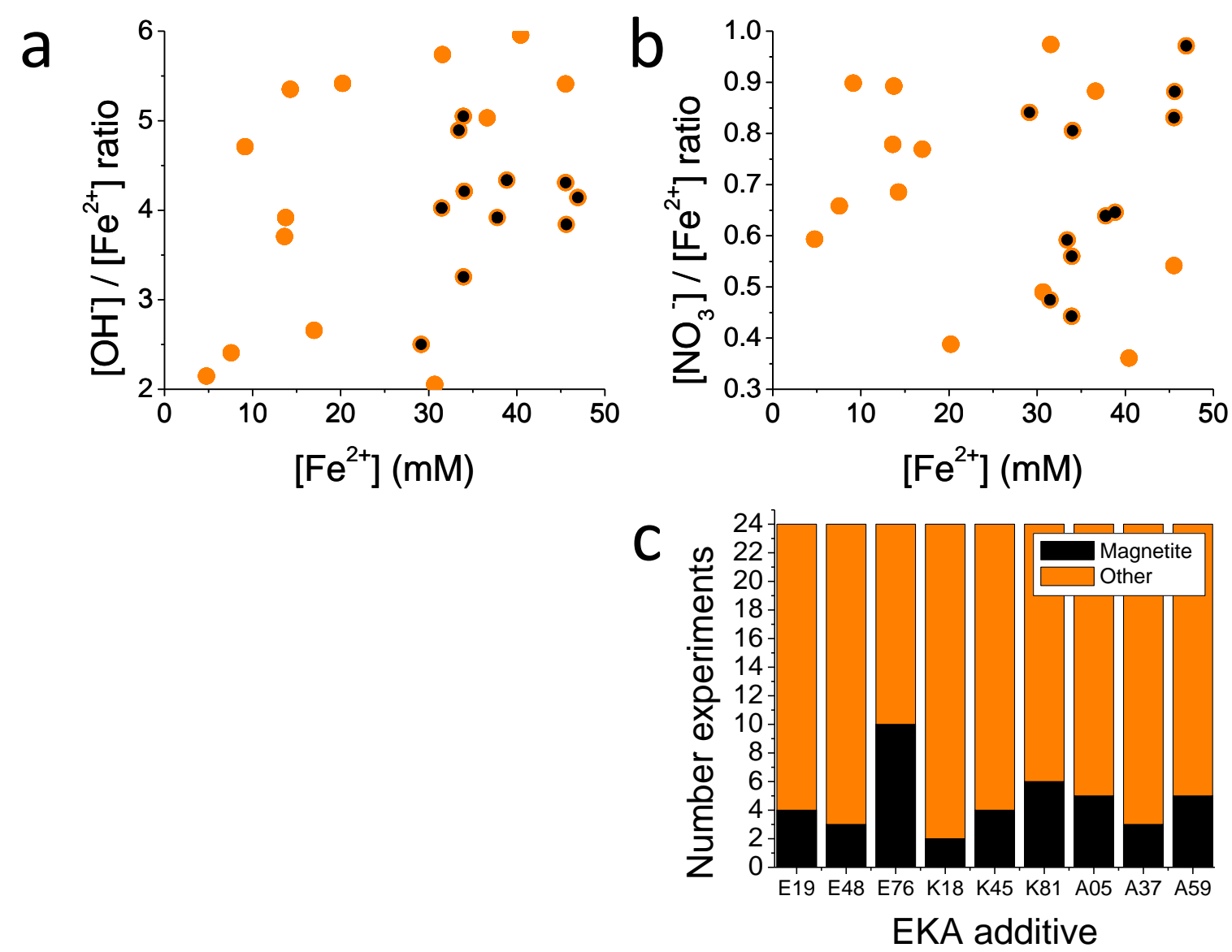

Figure S1 | Scatter plots of the randomly generated reactant concentrations for the 240 first round (parent) experiments: a) $\left[\mathrm{OH}^{-}\right] /\left[\mathrm{Fe}^{2+}\right]$ ratio and b) $\left[\mathrm{NO}_{3}{ }^{-}\right] /\left[\mathrm{Fe}^{2+}\right]$ ratio plotted against the $\mathrm{Fe}^{2+}$ concentration. c) Column diagram of the outcome of all experiments using the different EKA copolymers. The color codes are all as in c): black = successful conversion to magnetite, orange $=$ unsuccessful conversion to other iron (oxyhydr)oxides. 

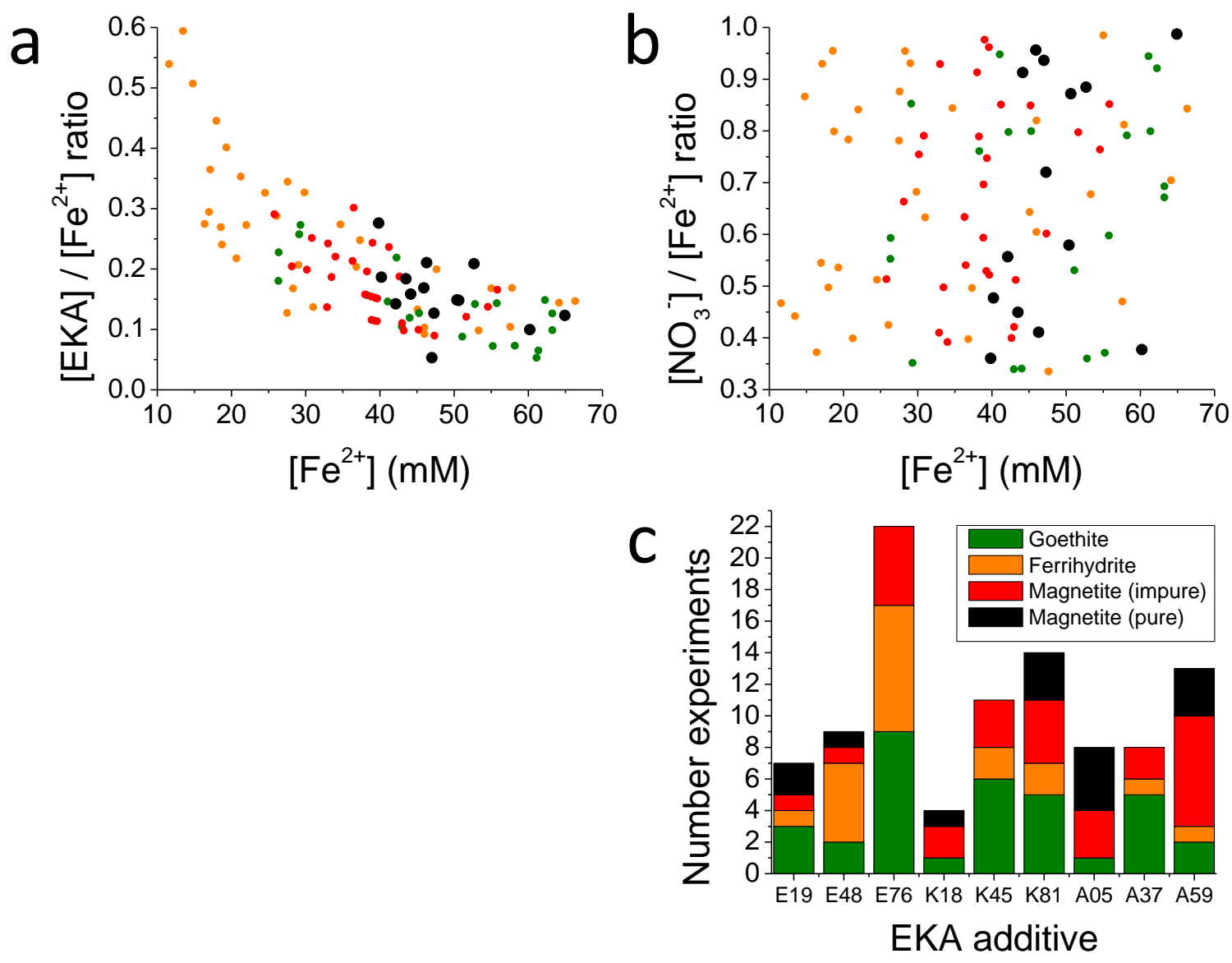

Figure S2 | Scatter plots of the genetically optimized reactant concentrations for the 96 second round (daughter) experiments: a) $[\mathrm{EKA}] /\left[\mathrm{Fe}^{2+}\right]$ ratio and b) $\left[\mathrm{NO}_{3}{ }^{-}\right] /\left[\mathrm{Fe}^{2+}\right]$ ratio plotted against the $\mathrm{Fe}^{2+}$ concentration. c) Column diagram of the outcome of all experiments using the different EKA copolymers. The color codes are all as in $\mathrm{c}$ ): green $=$ goethite, orange $=$ ferrihydrite, red $=$ multi-phase mixtures with magnetite and black = phase-pure magnetite . 

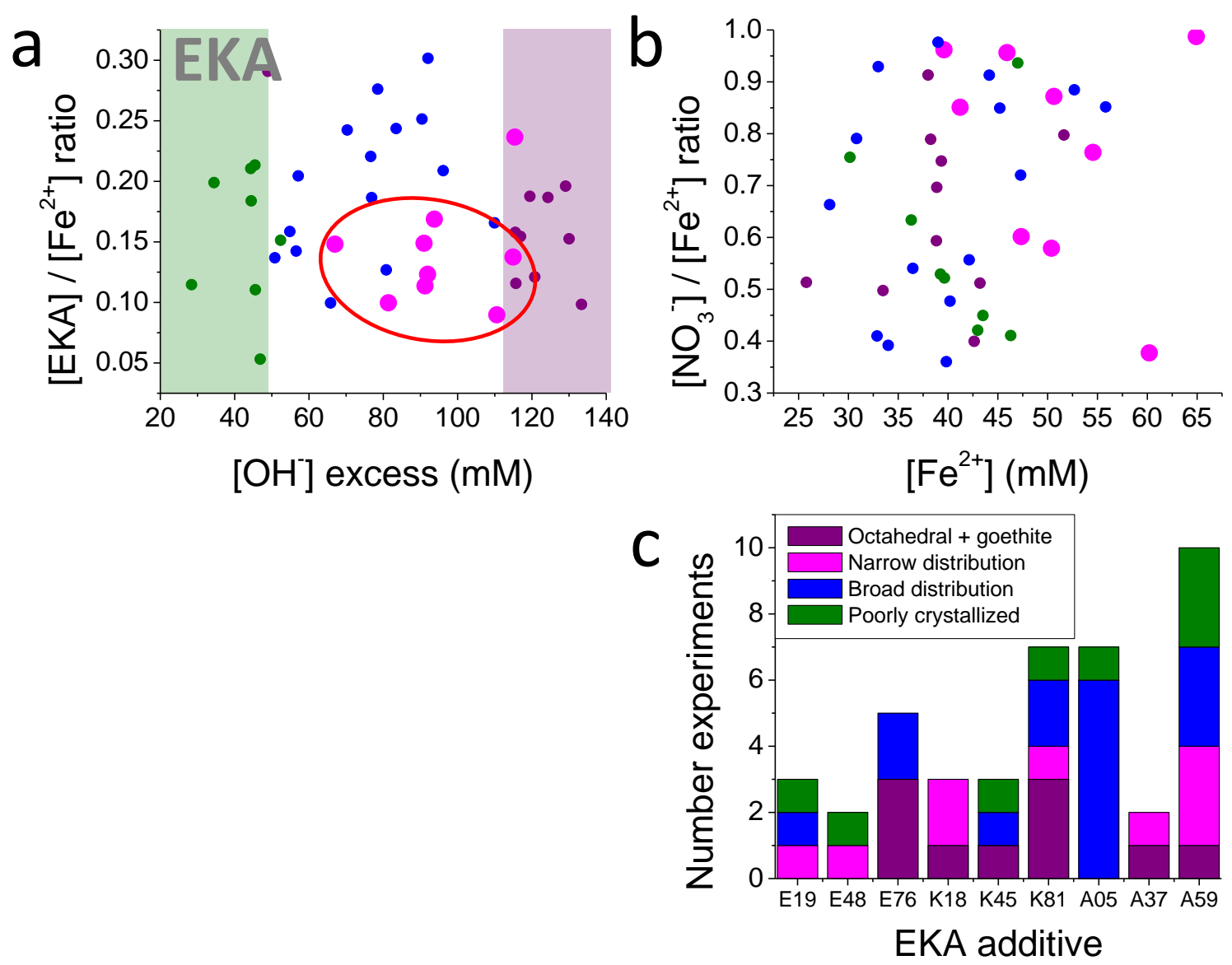

Figure S3 | Scatter plots of the genetically optimized reactant concentrations for the 42 successful second round (daughter) experiments: a) $[\mathrm{EKA}] /\left[\mathrm{Fe}^{2+}\right]$ ratio plotted against the $\left[\mathrm{OH}^{-}\right]$excess and b) $\left[\mathrm{NO}_{3}{ }^{-}\right] /\left[\mathrm{Fe}^{2+}\right]$ ratio plotted against the $\mathrm{Fe}^{2+}$ concentration. c) Column diagram of the outcome of all experiments using the different EKA copolymers. The color codes are all as in c): purple $=$ octahedral magnetite crystals and goethite, pink $=$ magnetite with a narrow size distribution, blue $=$ magnetite with a broad size distribution, green $=$ poorly crystallized magnetite. 

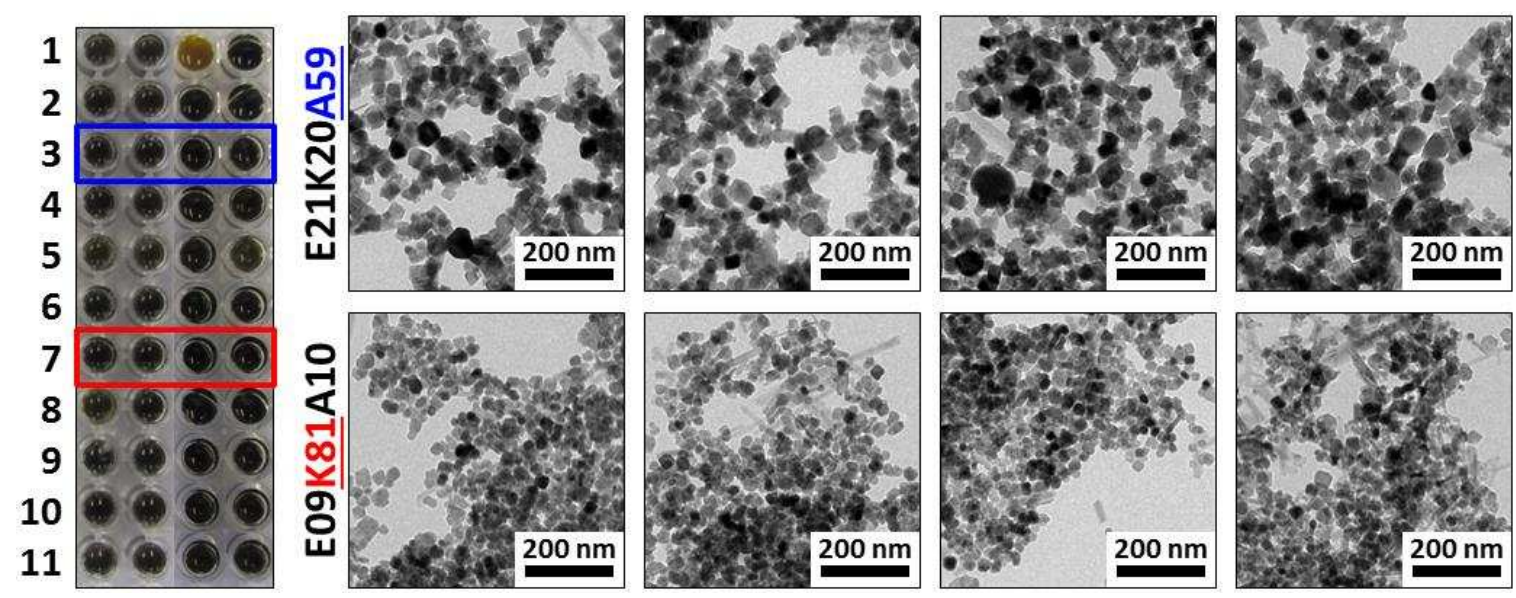

Figure S4 | Pictures of the 11 experiments that gave well-defined magnetite crystals in the first and second screening generations, and which were therefore selected as parent reactions for the $3^{\text {rd }}$ screening round. Parent reaction conditions were examined by conducting 4 replicates of each reaction; shown are TEM images corresponding with the 4 repeats of 2 selected experiments (3 and 7, using $\mathbf{A 5 9}$ and $\mathbf{K 8 1}$ as the additive, respectively). The experiments showed a good reproducibility, with only the third repeat of the first experiment (non-magnetic) being a clear outlier. The reason for this is unclear. All other results were similar to the original experiments. 

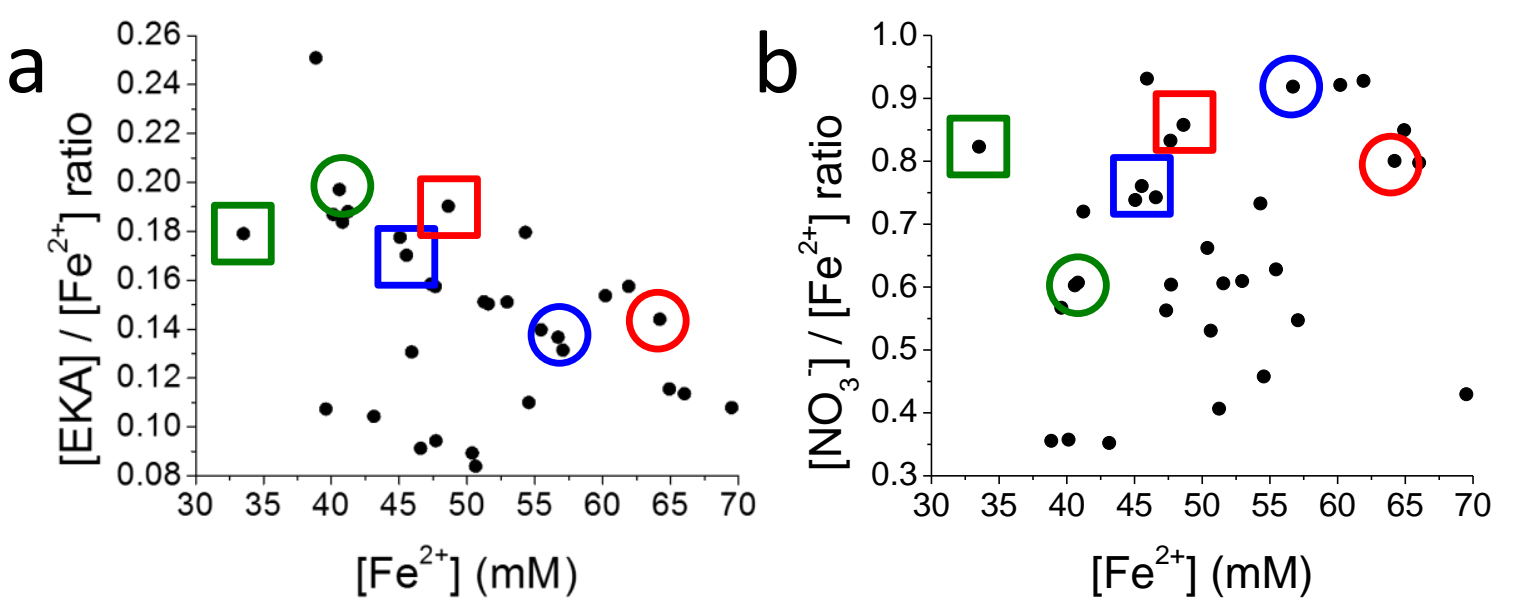

Figure S5 | Scatter plots of the genetically optimized reactant concentrations for the $3 \times 32$ third round (granddaughter) experiments: a) $[\mathrm{EKA}] /\left[\mathrm{Fe}^{2+}\right]$ ratio and b) $\left[\mathrm{NO}_{3}{ }^{-}\right] /\left[\mathrm{Fe}^{2+}\right]$ ratio plotted against the $\mathrm{Fe}^{2+}$ concentration. The circles and squares indicate for selected experiments which wells in Figure 6a in the main text correspond to which combinations of reactant concentrations. 


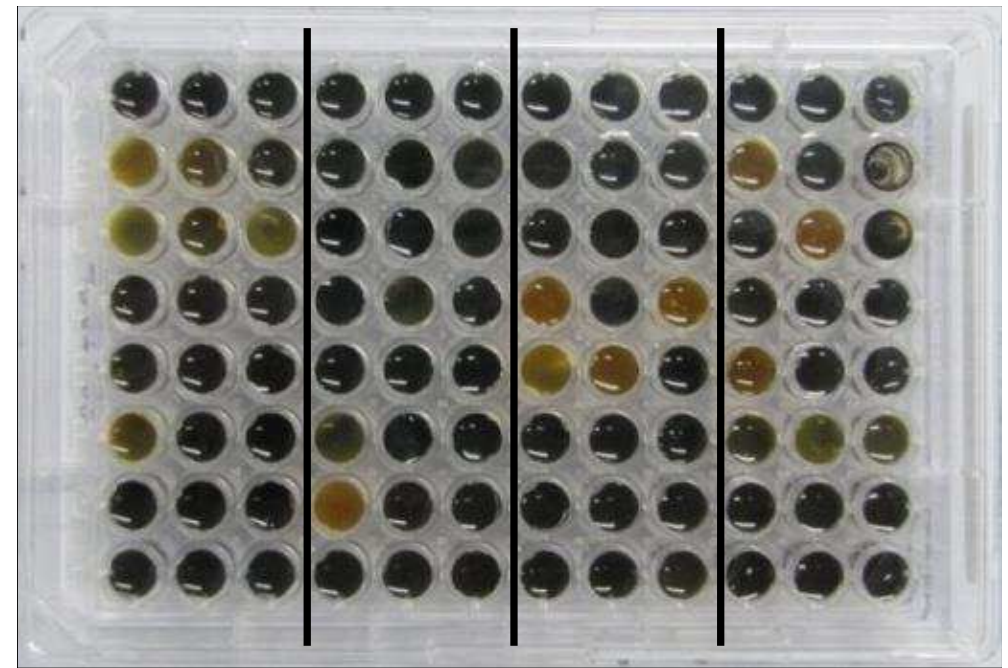

Figure S6 | Picture of the 96-well plate containing the products of the control experiments without the EKA copolymer additives of the 32 experiments to assess the role of the additive composition, all repeated 3 times, showing poor reproducibility. Each horizontal line of wells contains 4 unique experiments carried out 3 times. 

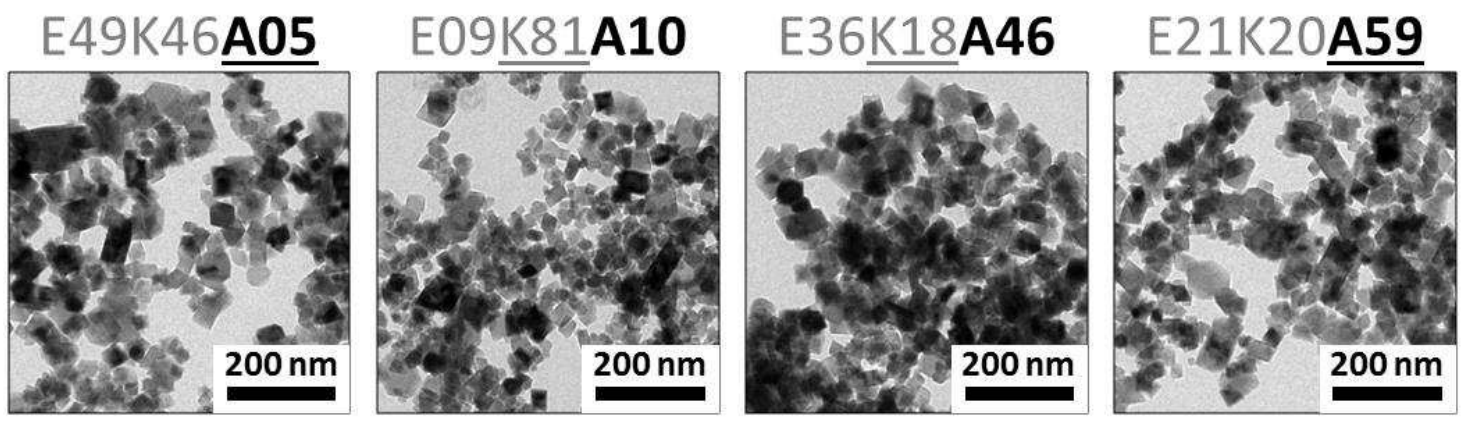

Figure S7 | Typical TEM images of magnetite products in the $50-70 \mathrm{mM} \mathrm{Fe} \mathrm{Fe}^{2+} / 80-120 \mathrm{mM}$ $\mathrm{OH}^{-}$excess parameter space with $\mathbf{A 0 5}, \mathbf{K 8 1}, \mathbf{K 1 8}$ and $\mathbf{A 5 9}$ as additives at a $[\mathrm{EKA}] /\left[\mathrm{Fe}^{2+}\right]$ ratio of $\sim 1 / 40$, showing little difference between all experiments. For the control reaction without polymer, see Figure S8. 

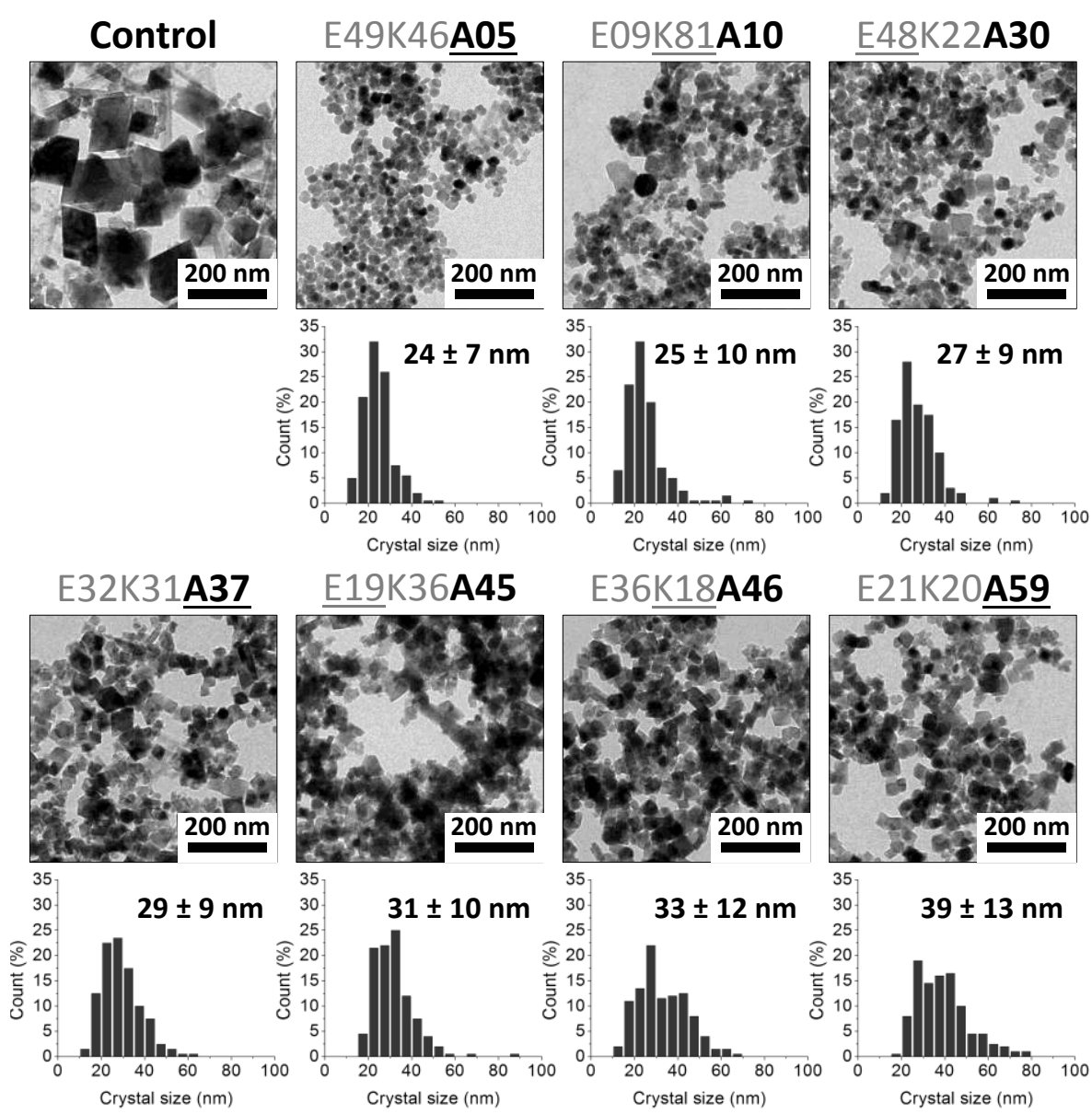

Figure S8 | Comparing experiments without (Control) or with all different EKA additives at a [EKA] $/\left[\mathrm{Fe}^{2+}\right]$ ratio of $\sim 1 / 8$, in a narrow subset of conditions $\left(50 \mathrm{mM}<\left[\mathrm{Fe}^{2+}\right]<70 \mathrm{mM}, 80\right.$ $\mathrm{mM}<\left[\mathrm{OH}^{-}\right]_{\text {excess }}<120 \mathrm{mM}$ ) from all experiments. Typical TEM images and size histograms of the products, showing a trend from smaller $(\sim 24 \mathrm{~nm})$, rounded particles to larger $(\sim 39 \mathrm{~nm})$, facetted crystals, depending on the A content of the copolymers. Statistical analyses showed that the increases in mean particle size are small but significant between $\mathbf{K 8 1}$ and $\mathbf{E 4 8}$ (t(398) $=2.65, \mathrm{p}=0.0083), \mathbf{A 3 7}$ and $\mathbf{E 1 9}(\mathrm{t}(398)=2.63, \mathrm{p}=0.0088)$ and $\mathbf{K 1 8}$ and $\mathbf{A 5 9}(\mathrm{t}(398)=5.20$, $\mathrm{p}<0.001$ ), for which the steps in the increasing A content indeed are rather large. The differences in average crystal size were found to be insignificant between $\mathbf{A 0 5}$ and $\mathbf{K 8 1}$ (t(361) $=0.76, \mathrm{p}=0.45), \mathbf{E 4 8}$ and A37 $(\mathrm{t}(398)=1.77, \mathrm{p}=0.077)$ and E19 and $\mathbf{K 1 8}(\mathrm{t}(384)=1.34, \mathrm{p}=$ 
0.18), for which the A contents are similar as well. Further, in all cases the relative width of the size distribution was $\sim 30 \%$. 